\title{
Dopamine, Cognitive Flexibility and IQ: Epistatic COMT:DRD2 Gene-Gene Interactions Modulate Mental Rigidity
}

\section{Authors}

Leor Zmigrod $^{1,2}$ \& Trevor W Robbins ${ }^{1,2}$

\author{
Affiliations \\ ${ }^{1}$ Department of Psychology, University of Cambridge, Cambridge, UK, \\ ${ }^{2}$ Behavioural and Clinical Neuroscience Institute, University of Cambridge, Cambridge, UK
}

This paper is currently in press at Journal of Cognitive Neuroscience. It can be cited as:

Zmigrod, L., \& Robbins, T. W. (2021). Dopamine, Cognitive Flexibility and IQ: Epistatic COMT:DRD2 Gene-Gene Interactions Modulate Mental Rigidity. https://doi.org/10.31234/osf.io/2wqgm

Please contact Dr Leor Zmigrod lz343@ cam.ac.uk for any questions.

\begin{abstract}
Cognitive flexibility has been hypothesized to be neurochemically rooted in dopamine neurotransmission. Nonetheless, underpowered sample sizes and contradictory meta-analytic findings have obscured the role of dopamine genes in cognitive flexibility and neglected potential gene-gene interactions. In this largest neurocognitive-genetic study to date $(\mathrm{N}=1400)$, single nucleotide polymorphisms associated with elevated prefrontal dopamine levels (Catechol-O-MethylTransferase, COMT; rs4680) and diminished striatal dopamine (C957T; rs6277) were both implicated in Wisconsin Card Sorting Test performance. Crucially, however, these genetic effects were only evident in low-IQ participants, suggesting high intelligence compensates for, and eliminates, the effect of dispositional dopamine functioning on flexibility. This interaction between cognitive systems may explain and resolve previous
\end{abstract}


empirical inconsistencies in highly educated participant samples. Moreover, compensatory gene-gene interactions were discovered between COMT and DRD2, such that genotypes conferring either elevated prefrontal dopamine or diminished striatal dopamine - via heightened striatally-concentrated D2 dopamine receptor availability - are sufficient for cognitive flexibility, but neither is necessary. The study has therefore revealed a form of epistatic redundancy or substitutability amongst dopamine systems in shaping adaptable thought and action, thus defining boundary conditions for dopaminergic effects on flexible behavior. These results inform theories of clinical disorders and psychopharmacological interventions and uncover complex fronto-striatal synergies in human flexible cognition.

\section{Keywords}

Cognitive flexibility, dopamine, COMT, DRD2, Wisconsin Card Sorting Test, intelligence, interactions, epistasis, neurocognitive genetic methodology 


\section{Introduction}

Flexible adaptation of behavior in the face of changing environments is a core feature of human cognition, especially when confronted with a multifaceted and rapidly-changing world. In normative contexts, impairment in cognitive flexibility can lead to maladaptive habitual tendencies and associated difficulties with goal-directed behavior when task demands change. In more extreme cases, cognitive rigidity can be a characteristic of neuropsychiatric disorders of compulsivity such as obsessive-compulsive disorder and drug addiction (Figee et al., 2016; Chamberlain et al., 2007, 2021; Ersche et al 2008). Theoretical and empirical approaches have suggested that individual differences in cognitive flexibility may be neurochemically rooted in dopaminergic systems (Cools \& D'Esposito, 2011), yet insufficient statistical power due to small sample sizes as well as contradictory meta-analytic results (e.g. Barnett, Jones, Robbins, \& Muller, 2007; Barnett, Scoriel, \& Munafo, 2008; Flint \& Munafo, 2006; Mier, Kiursch, \& Meyer-Lindenberg, 2010) have hampered the development of a robust understanding of the dopaminergic basis of flexibility in humans. Studies have often consisted of fewer than 150 participants (most commonly including fewer than 50 participants), who are typically highly educated university students. As a result, several researchers have argued that past efforts to investigate the role of dopamine genes in cognitive flexibility have been severely underpowered (see Barnett et al., 2007; Flint \& Munafo, 2007; Savitz, Solms, \& Ramesar, 2006). This has also rendered nuanced analyses of moderating variables and gene-gene interactions nearly impossible. Given that many psychopharmacological treatments of disorders of compulsivity, or of aberrant cognitive control, rely on medication that potentiates and increases dopamine, elucidating the dopaminergic mechanisms underlying cognitive flexibility is a pressing conceptual and clinically-relevant issue.

The cognitive control processes associated with flexibility - including the ability to suppress habitual actions, attend to dimensionally-relevant stimuli, and alter behavior 
according to novel task-demands - have implicated the prefrontal cortex (PFC), a brain area rich in dopamine (DA) D1 receptors compared with D2 receptors (Lidow et al 1991; GoldmanRakic, 1995) and highly sensitive to its dopaminergic environment (Cools \& D’Esposito, 2011b). This has directed neuroscientists and behavioral geneticists towards evaluating the role of the Val158Met SNP in the catechol-O-methyltransferase (COMT) gene (rs4680) on 22q11, which is responsible for over $60 \%$ of the enzymatic degradation of DA in the prefrontal cortex (Yavich, Forsberg, Karayiorgou, Gogos, \& Mannisto, 2007). The Met allele of the COMT gene has approximately a quarter of the enzymatic activity of its counterpart, the Val allele (Lachman, Papolos, Saito, Yu, Szumlanski, 1996; Chen et al., 2004), and so individuals with the low-activity Met allele will have lower COMT DA-elimination activity. Low COMT activity translates to higher levels of synaptic dopamine in the prefrontal cortex. In contrast, individuals with a $\mathrm{Val} / \mathrm{Val}$ genotype - with high COMT activity - are assumed to have lower PFC dopamine levels. The higher levels of prefrontal dopamine in Met-carriers have been linked to better performance on prefrontally-mediated cognitive tasks in general (e.g. Egan et al., 2001; Diamond et al., 2004; Frank et al., 2007; Frank et al., 2009; Mier et al., 2010), and cognitive flexibility on the 'gold-standard' Wisconsin Card Sorting Test (WCST) in particular (e.g. Malhotra et al., 2002; Barnett et al., 2007).

Nonetheless, the effect of COMT genotype on WCST performance has been hotly debated over the last three decades - with some studies and meta-analyses identifying a strong effect of Val/Met alleles and others reporting null findings - and much ink has been spilled over whether, how, why, and to what extent COMT genotype shapes cognitive flexibility on this task (e.g. Goldman, Weinberger, Malhotra, \& Goldberg, 2009; Barnett, Scoriels, \& Munafo, 2011; Wacker, 2011). Several meta-analyses have corroborated the theory that Metcarriers, with high baseline PFC DA levels, exhibit better performance on the WCST (e.g. Barnett, Jones, Robbins, \& Muller, 2007; Flint \& Munafo, 2006; Mier, Kiursch, \& Meyer- 
Lindenberg, 2010). Yet other meta-analyses have not found the reported effect: in a contested (Goldman et al., 2009; Wacker, 2011) conclusion, Barnett, Scoriels, and Munafo (2008) asserted that "the COMT Val158/108Met polymorphism appears to have little if any association with cognitive function." As observed by Wacker (2011), these discussions and meta-analyses are highly cited and highly influential for the field, and so careful and wellpowered interpretation is critical. The COMT-WCST relationship is considered such a hallmark of the discipline that Flint and Munafo (2006) argued that the "analysis of the association between COMT genotype and WCST performance should provide a good test of the value of the endophenotype approach in genetics". It was therefore the intention of the present investigation to disambiguate between past contradictory accounts by acquiring a sufficiently large and well-powered sample to evaluate the relationship between COMT and WCST performance - and thereby test one of the most prominent theories that a geneticallygrounded endophenotypic approach is fruitful and productive.

In addition to the role of prefrontal dopaminergic systems, animal research and neurogenetic work have indicated that the aetiology of cognitive flexibility may also be shaped by striatal dopamine, particularly through the impact of dopamine D2 receptors which are highly concentrated and expressed in the striatum rather than the cerebral cortex (Lidow et al 1989). In animals, lesioning the caudate nucleus of the striatum (Clarke, Robbins, \& Roberts, 2008; Divac, Rosvold, \& Szwarcbart, 1967) or its homologue in rats' dorsomedial striatum (Kirkby, 1969; Lindgren, Wickens, Tait, Brown, \& Dunnett, 2013; Ragozzino, 2007; Castañé, Theobald, \& Robbins, 2010) results in dysfunctional perseveration during reversal learning. More specifically, selective dopaminergic depletion of the caudate nucleus impaired reversal in marmoset monkeys (Clarke, Hill, Robbins, \& Roberts, 2011) and in the homologous dorsomedial striatum in rats (O’Neill, \& Brown, 2007), signifying that striatal dopamine transmission is essential for flexible behavior. Pharmacological evidence further corroborates 
the contribution of striatal dopamine towards flexible adaptation (e.g. Horst, Jupp, Roberts, \& Robbins, 2019). Nonetheless, results have been equivocal with regards to the specific role of dopamine D2 receptors play in flexible behavior; the D2/D3 antagonist raclopride (Lee, Groman, London, \& Jentsch, 2007) and an opposing-action D2/D3 agonist quinpirole (Boulougouris, Castañé, \& Robbins, 2009) have both produced deficits in reversal learning in animals (see Floresco 2013 for review). Pharmacological findings in humans have also pointed to complex mechanisms implicating D2 receptor binding in flexibility (e.g. Cools, Barker, Sahakian, \& Robbins, 2003; Ersche, et al., 2011; Mehta, Manes, Magnol, Sahakian, \& Robbins, 2004).

Several streams of research suggest that genetic differences in DRD2-mediated dopamine signaling may impact cognitive flexibility in humans (e.g. Jocham et al., 2009; Volkow et al., 1998). Two polymorphisms in the D2 receptor gene DRD2 have garnered particular attention: the C957T (rs6277) polymorphism and the ANKK1/Taq1A (rs1800497) polymorphism. The DRD2 C957T polymorphism has been shown to influence D2 receptor availability in the striatum, with the $\mathrm{CC}$ genotype exhibiting lower striatal D2 receptor availability than T-carriers (Hirvonen, et al., 2004, 2005, 2009). High D2 receptor availability should presumably correspond to low synaptic concentration of dopamine, and vice versa (Gluskin \& Mickey, 2016; Hagelberg et al., 2004; Hirvonen et al., 2004, 2009; Laruelle, 2000). Rodriguez-Jimenez and colleagues (2006) found that T-carriers performed better on the WCST, suggesting an advantage for individuals with higher striatal D2 receptor availability. But Rodriguez-Jimenez and colleagues (2006) acknowledged that their sample size was limited $(\mathrm{N}=83)$ and their participants were all university-educated, thus restricting the generalizability of the findings.

The second relevant DRD2 polymorphism, ANKK1/Taq1a, has been linked to dopamine D2 receptor density in the striatum, with A1-carriers possessing $30 \%$ fewer 
dopamine D2 receptor binding sites relative to non-A1-carriers (Ritchie \& Noble, 2003). A1carriers struggle to learn from errors in probabilistic learning tasks (Klein et al., 2007; Jocham et al., 2009), exhibiting reduced recruitment of the ventral striatum and frontal areas during reversals (Jocham et al., 2009). Correspondingly, A1-carriers have higher rates of psychopathology in disorders of compulsivity such as addiction (Bowirrat \& Oscar-Berman, 2005) and compulsive gambling (Comings et al., 1996).

A recent meta-analysis by Klaus and colleagues (2019) on the effect of DRD2 polymorphisms C957T (across 3 studies) and Taq1A (across 4 studies) on cognitive flexibility did not find a significant effect of these polymorphisms when pooling several types of cognitive flexibility tasks together. However, when sensitivity analyses were conducted on the WCST alone, there was evidence that $\mathrm{C} / \mathrm{C}$ homozygotes on the $\mathrm{C} 957 \mathrm{~T}$ polymorphism exhibited significantly worse performance relative to $\mathrm{C} / \mathrm{T}$ or $\mathrm{T} / \mathrm{T}$ groups. There was no evidence for an effect of the ANKK1/Taq1A polymorphism. Consequently, we also sought to resolve the debate regarding the role of DRD2 polymorphisms in cognitive flexibility on the WCST in healthy participants through a well-powered analysis to examine whether C957T C-carriers perform poorly on the WCST, and whether the ANKK1/Taq1A polymorphism is implicated in flexibility at all.

In sum, the present investigation examined how genes affiliated with prefrontal dopamine neurotransmission (COMT) and striatally-concentrated dopamine receptors (C957T and ANKK1/Taq1A) impact cognitive flexibility. Neurogenetic work on dopamine and endophenotypes of psychopathology has identified a specific connection between dopamine and cognitive ability (Gothelf et al., 2005; Meyer-Lindenberg \& Weinberger, 2006) and so we measured intelligence in order to isolate the precise effects of dopamine on cognitive flexibility when taking cognitive ability into account. To the best of our knowledge, we recruited a sample $(\mathrm{N}=1400)$ larger than any previous individual study dedicated to these questions, and larger 
than many meta-analyses on the relationship between dopamine and cognitive flexibility. This allows for nuanced analyses of epistatic gene-gene interactions and flexibility-IQ interactions. These gene-gene interactions may reflect biological epistasis (Domingo, Baeza-Centurion, \& Lehner, 2019), which takes place when "the effect of an allele in one gene implicated in a complex, non-linear biological function is critically dependent on alleles in other genes that impact on the same non-linear function" (Papaleo, Burdick, Callicott, \& Weinberger, 2013). The study thereby aims to resolve existing debates about the genetic roots of flexible behavior and forge a path forward for cognitive and clinically-oriented research in psychopathology and psychopharmacology.

\section{Methods}

\section{Participants and SNP selection}

Participants were recruited from the United Kingdom's National Institute for Health Research (NIHR) BioResource pool, which consists of a community of volunteers who have previously been genotyped and are willing to participate in non-invasive studies for free. To motivate participation and performance, participants could choose to opt-in for a lottery to win Amazon vouchers. There were three Amazon vouchers worth $£ 50$ and five vouchers worth $£ 10$. It was made clear that this is a lottery, and at the end of the study eight random anonymous participants were contacted and awarded the vouchers.

Participants who fulfilled the inclusion criteria were sent an e-mail invitation with the study information, consent forms, and online access to the study. Participants provided their informed consent to participate in the study in accordance with the University of Cambridge's Department of Psychology Ethics Committee approval (Ref 2017/18-27). The study link directed them to Qualtrics, where they completed surveys and the Raven's Standard 
Progressive Matrices (SPM), and later to Inquisit Millisecond, where the Wisconsin Card Sorting Test was administered online.

Participants were recalled based on two SNPs of interest: rs4680 (COMT) and rs1800497 (DRD2 ANKK1/Taq1A), such that approximately equal proportions of the nine possible groups (of minor/major allele heterozygosity and homozygosity) were targeted in each batch of participant invitations. The fact that minor/minor SNP expression might reduce the frequency of those groups was acknowledged. BioResource further ensured that the genotype groups were matched by gender, ethnicity, and age, within 5-10 years. Inclusion criteria were restricted to participants who are over 18 years old and under 75 , and had previously been genotyped for the required SNPs. Participants were contacted in waves between November 2018 and June 2019.

These SNPs were selected based on the literature connecting cognitive flexibility and these two dopaminergic genes (COMT: Barnett, Jones, Robbins, \& Muller, 2007; Frank et al., 2017; DRD2: Frank \& Fosella, 2011; Savitz et al., 2006; Markett et al., 2011; Stelzel et al., 2010; Klanker, Feenstra, \& Denys, 2013; COMT-DRD2 interactions in cognitive functions: Stelzel et al., 2009; Garcia-Garcia et al., 2017). We further requested existing available information on DRD2 (rs6277) given the literature implicating striatal dopamine in cognitive flexibility (Kehagia, Murray, \& Robbins, 2010; Vaghi et al., 2017; van Holstein et al., 2011) and associated learning processes (Frank, Doll, Oas-Terpstra, \& Moreno, 2009; Doll, Hutchison, \& Frank, 2011). These three dopaminergic genes have been studied together in domains adjacent to WCST cognitive flexibility (Berryhill et al., 2013; Bolton et al., 2010; GarciaGarcia et al., 2017; Klaus et al., 2017; Zhang, Zhang, \& Zhang, 2014), but to the best of our knowledge, not in WCST directly. 


\section{$\underline{\text { Tasks }}$}

\section{Cognitive Flexibility - Wisconsin Card Sorting Test (WCST)}

The Wisconsin Card Sorting Test (WCST) was administered with Inquisit 5 by Millisecond Software in standard fashion (Heaton, 1981). Participants are presented with four key cards and a deck of response cards that vary on three dimensions (color, shape, and number of geometric figures) and are asked to match a fifth card from the sequentially presented response cards to one of the four key cards. There are various potential rules that can underpin the classification, for instance matching the cards by shape, number, or color. Participants are required to identify and apply the correct card classification rule in accordance with the feedback they receive after each trial. Participants are informed at the start of the task that the card classification rule can change without warning. Correspondingly, after participants correctly respond to 10 consecutive trials the classification rule changes, requiring a flexible set shift. The task terminates after participants complete six categories (twice for each of the three classification rules) or after 128 trials. Participants' performance is indexed through the accuracy rate during the task.

Intelligence - Raven's Standard Progressive Matrices Task (Raven's SPM)

An abbreviated version of the Raven's SPM (Bilker et al., 2012; Raven, 1938) was used to assess fluid intelligence. The task was composed of nine visual patterns which progressively increased in difficulty. For each matrix pattern, one piece was missing, and participants are asked to select the correct pattern piece from a set of possible solutions.

\section{Analytic Strategy}

Analysis was conducted using R (R Core Team, 2020), JASP (JASP Team, 2020), and SPSS (Version 27.0; IBM Corp., 2020). A series of univariate Analyses of Covariance (ANCOVA) were computed for (1) low IQ participants (Raven's SPM score $<6$; N=498 (483 with full age 
and gender data)), (2) median IQ participants (Raven's SPM score =6; N=265 (256 with full age and gender data)), and (3) high IQ participants (Raven's SPM score $>6$; N=671 (661 with full age and gender data)), and (4) the whole sample ( $\mathrm{N}=1434$ (1400)). For the outcome variable, WCST performance was indexed by the accuracy rate. This conforms with past research on healthy participants (e.g. Zmigrod, Rentfrow, \& Robbins, 2018, 2019) as it captures sufficient variation amongst individual differences for meaningful analyses to be conducted. Due to software issues with the task administering platform, Inquisit Millisecond, the calculation of perseverative errors was not possible. As an additional robustness check to ensure that analyses tapped at flexibility and were not confounded by cognitive ability, analyses were replicated on the residuals of WCST accuracy rate after accounting for IQ (outcome variable $=$ standardized residuals of WCST $\sim$ IQ). The standardized residuals were computed through a regression on the whole sample. Age and gender were included as covariates in all analyses unless otherwise stated. The primary genotype analyses pooled participants into two potential genotype groups for each SNP examined, putting together the heterogeneous group with one of the homogenous groups in accordance with existing literature conventions and standards. For COMT, Met-carriers were pooled together. For DRD2 C957T, C-carriers were pooled together. For DRD2 ANKK1/Taq1A, A1-carriers were pooled together. In the Appendix, we also provide analyses conducted on the three original SNP groups for each gene.

\section{Results}

\section{WCST and COMT}

General linear models in the form of univariate Analyses of Covariance (ANCOVA) were computed with WCST accuracy rate as the outcome variable for (1) low IQ participants, (2) median IQ participants, and (3) high IQ participants, and (4) the whole sample. Age and gender 
were included as covariates, and COMT genotype (Met-carriers vs Val/Val genotype) was the fixed factor predictor.

As manifest in Figure 1, in low IQ participants, the ANCOVA revealed a significant difference between Met-carriers and Val/Val genotypes, $\mathrm{F}(1,479)=4.521, p=0.034$, Cohen's $\mathrm{d}=0.208$ (Table 1, Figure 1), with Met-carriers exhibiting better WCST performance than Val/Val genotypes. This was also corroborated by an independent samples t-test, which does not control for age and gender, which revealed that Met-carriers were more accurate on the WCST than Val/Val genotypes, $\mathrm{t}(496)=2.139, p=0.033$, Cohen's $\mathrm{d}=0.210$.

$1 \mathrm{~A}$

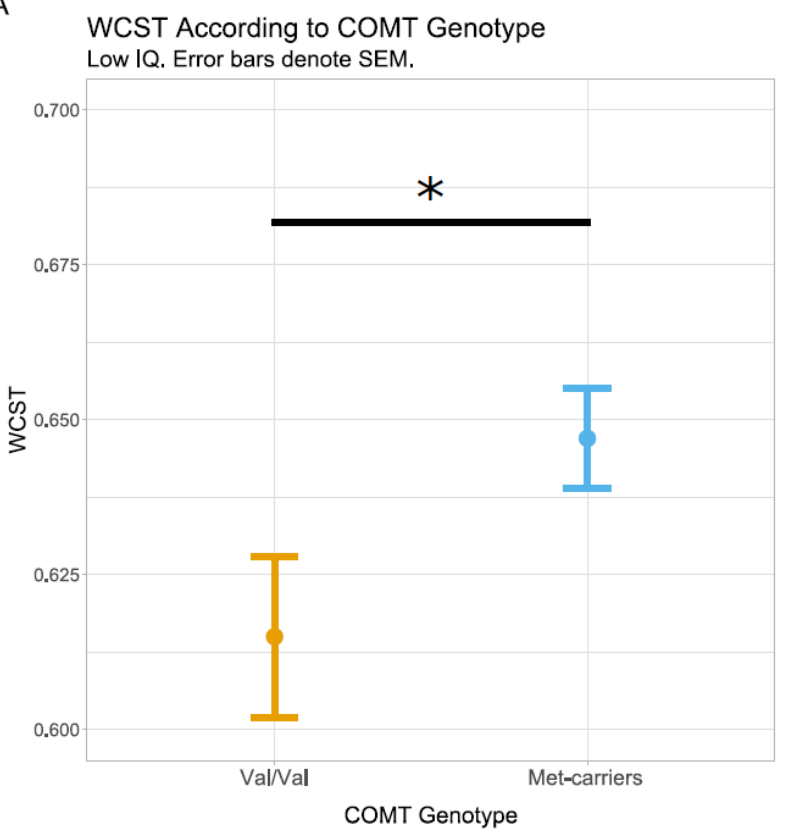

$1 \mathrm{~B}$

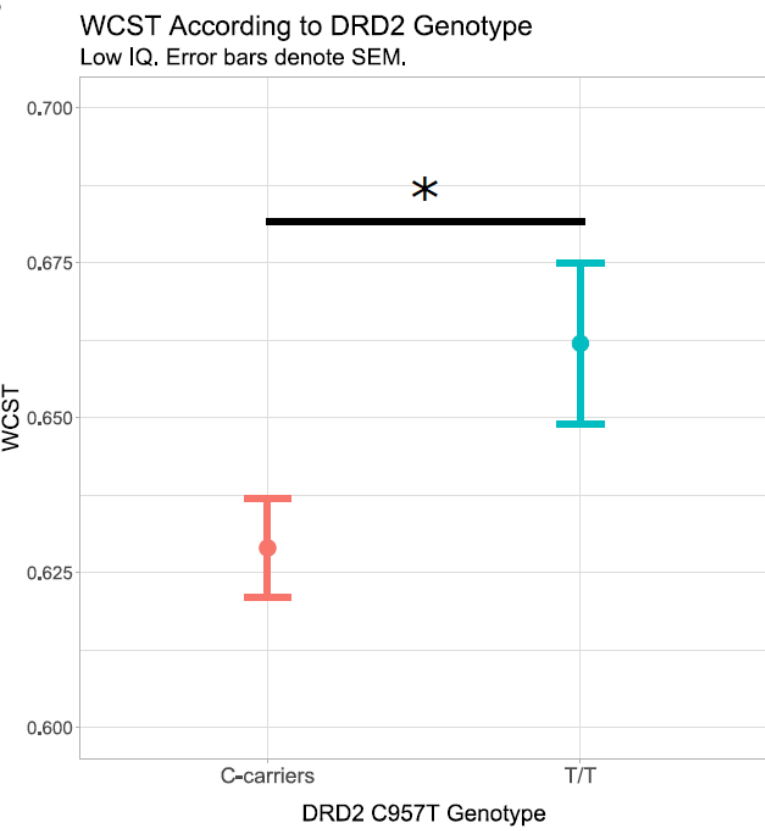

Figure 1. WCST accuracy rate according to (A) COMT genotype and (B) DRD2 C957T genotype, in low IQ participants, controlling for age and gender. ${ }^{*} p<.05$.

Table 1. ANCOVA on WCST accuracy rate according to COMT genotype in low IQ participants.

COMT (Low IQ)

\begin{tabular}{llllll}
\hline COMT Genotype & N & M & SEM & 95\% CI LB & 95\% CI UB \\
\hline Met-carriers & 341 & 0.647 & 0.008 & 0.631 & 0.663 \\
Val/Val & 142 & 0.615 & 0.013 & 0.590 & 0.640 \\
\cline { 2 - 6 } & SS & F & df & $\boldsymbol{p}$ & $\boldsymbol{\eta}^{\mathbf{2}}$ \\
\hline
\end{tabular}




\begin{tabular}{llllll}
\hline COMT Genotype & N & M & SEM & 95\% CI LB & 95\% CI UB \\
\hline & 0.101 & 4.521 & 1,479 & 0.034 & 0.009
\end{tabular}

$\mathrm{M}=$ Marginal mean, controlling for age and gender. $\mathrm{SE}=$ standard error of mean. $\mathrm{CI}=$ confidence interval. $\mathrm{LB}=$ lower bound. UB=upper bound. SS=Type III Sum of Squares for COMT effect on WCST accuracy rate.

In contrast, the ANCOVAs on the other subgroups and the whole sample did not detect significant differences in WCST performance between COMT genotype groups. COMT genotype was not a significant predictor for median IQ participants, $\mathrm{F}(1,252)=0.015, p=0.902$, for high IQ participants, $\mathrm{F}(1,657)=0.959, \mathrm{p}=0.328$, or for the whole sample, $\mathrm{F}(1,1396)=0.651$, $p=0.420$. For an additional robustness check, an ANCOVA was conducted on the IQresidualized WCST accuracy rate as the outcome variable (see Methods section for more details), to ensure that cognitive ability did not confound the cognitive flexibility findings. As before, age and gender were included as covariates. This analysis corroborated the results found in the low IQ participants, illustrating that Met-carriers outperformed Val/Val genotyped individuals on the WCST, $\mathrm{F}(1,479)=5.108, p=.024, \eta_{\mathrm{p}}{ }^{2}=0.011$, Cohen's $\mathrm{d}=0.222$ (Met-carriers marginal mean $=0.056, \mathrm{SEM}=0.057,95 \% \mathrm{CI}=[-0.056,0.167], \mathrm{Val} / \mathrm{Val}$ marginal mean=-0.182, $\mathrm{SEM}=0.088,95 \% \mathrm{CI}=[-0.355,-0.008])$.

\section{WCST and DRD2 C957T}

Univariate ANCOVAs were computed with WCST accuracy rate as the outcome variable, age and gender as covariates, and DRD2 C957T genotype (T/T versus C-carriers) as the fixed factor predictor. As manifest in Figure 1, in low IQ participants, the ANCOVA revealed a significant difference between T/T and C-carrier genotypes, $\mathrm{F}(1,479)=4.641, p=0.032$, Cohen's $\mathrm{d}=0.216$ (Table 2, Figure 1), with T/T participants exhibiting better WCST performance than C-carriers. An independent samples t-test, which does not control for age and gender, also demonstrated that T/T genotypes were more accurate on the WCST than C-carriers genotypes, closely approaching statistical significance $\mathrm{t}(496)=1.919, p=0.055$, Cohen's $\mathrm{d}=0.193$. 
Table 2. ANCOVA on WCST accuracy rate according to DRD2 C957T genotype in low IQ participants.

DRD2 C957T (Low IQ)

\begin{tabular}{llllll}
\hline DRD2 Genotype & $\mathbf{N}$ & $\mathbf{M}$ & $\mathbf{S E M}$ & $\mathbf{9 5 \%}$ CI LB & $\mathbf{9 5 \%}$ CI UB \\
\hline T/T & 131 & 0.662 & 0.013 & 0.636 & 0.687 \\
C-carriers & 352 & 0.629 & 0.008 & 0.613 & 0.644 \\
\cline { 2 - 6 } & $\mathbf{S S}$ & $\mathbf{F}$ & $\mathbf{d f}$ & $\boldsymbol{p}$ & $\boldsymbol{\eta}^{\mathbf{2}} \mathbf{p}$ \\
\cline { 2 - 6 } & 0.103 & 4.641 & 1,479 & 0.032 & 0.010
\end{tabular}

$\mathrm{M}=$ Marginal mean, controlling for age and gender. $\mathrm{SE}=$ standard error of mean. $\mathrm{CI}=$ confidence interval. $\mathrm{LB}=$ lower bound. UB=upper bound. SS=Type III Sum of Squares for DRD2 C957T effect on WCST accuracy rate.

Unlike the findings for low IQ participants, the ANCOVAs on the other subgroups and the whole sample did not detect significant differences in WCST performance between C957T DRD2 genotype groups. C957T DRD2 genotype was not a significant predictor for median IQ participants, $\mathrm{F}(1,252)=0.200, p=0.655$, for high IQ participants, $\mathrm{F}(1,657)=0.234, p=0.629$, or for the whole sample, $\mathrm{F}(1,1396)=1.261, p=0.262$.

An additional robustness check was calculating through an ANCOVA on the IQ-residualized WCST accuracy rate as the outcome variable. Age and gender were included as covariates. This analysis largely supported the results found in the low IQ participants, showed that lowIQ T/T genotypes outperformed C-carriers on the WCST, nearly achieving statistical significance, $\quad F(1,479)=3.526, \quad p=.061, \quad \eta^{2}=0.007$, Cohen's $d=0.188 \quad(T / T$ marginal mean $=0.133, \mathrm{SEM}=0.092,95 \% \mathrm{CI}=[-0.047,0.314], \mathrm{C}$-carriers marginal mean $=-0.068$, $\mathrm{SEM}=0.056,95 \% \mathrm{CI}=[-0.179,0.042])$. 


\section{WCST and DRD2 ANKK1/Taq1A}

ANCOVAs were conducted on Taq1A DRD2 genotype as the fixed factor variable predicting WCST accuracy rate, controlling for age and education. There were no significant differences in WCST performance according to Taq1A DRD2 genotype on any subgroup or the whole sample. Taq1A DRD2 genotype was not a significant predictor in low IQ participants, $\mathrm{F}(1,479)=0.035, p=0.582$, in median IQ participants, $\mathrm{F}(1,252)=2.814, p=0.095$, in high IQ participants, $\mathrm{F}(1,657)=3.119, p=0.078$, or in the whole sample $\mathrm{F}(1,396)=0.150, p=0.698$.

In the median IQ and high IQ groups, although the role of Taq1A DRD2 genotype was not significant, the $p$-value was below 0.10 and so we examined whether notable patterns could be qualitatively extracted. However, the influence of Taq1A DRD2 genotypes was inconsistent across the two groups: in median IQ participants, A1-carriers (ANCOVA marginal mean $=0.719, \mathrm{SEM}=0.011,95 \% \mathrm{CI}=[0.696,0.741])$ performed better than $\mathrm{A} 2$ genotypes (marginal mean=0.689, SEM $=0.013,95 \% \mathrm{CI}=[0.663,0.715]$ ), whereas in high IQ participants, A1-carriers (ANCOVA marginal mean $=0.738, \quad \mathrm{SEM}=0.007,95 \% \quad \mathrm{CI}=[0.725,0.752])$ performed more poorly than A2 genotyped individuals (marginal mean=0.755, SEM=0.007, $95 \% \mathrm{CI}=[0.742,0.769])$.

Using the IQ-residualized WCST accuracy rate as the outcome variable did not affect the results: there were no significant differences according to Taq1A DRD2 genotype in low IQ participants, $\mathrm{F}(1,479)=0.00003, p=0.996$, in median IQ participants, $\mathrm{F}(1,252)=2.814, p=0.095$, in high IQ participants, $\mathrm{F}(1,657)=2.677, p=0.102$, or in the whole sample, $\mathrm{F}(1,1396)=0.020$, $p=0.889$. The pattern in median and high IQ participants was the same as when WCST accuracy rate was used as the outcome variable: in median IQ participants, A1-carriers (ANCOVA marginal mean $=0.148, \mathrm{SEM}=0.083,95 \% \mathrm{CI}=[-0.015,0.311])$ performed better than $\mathrm{A} 2$ genotypes (marginal mean=-0.066, SEM=0.096, 95\% CI=[-0.255, 0.124]), whereas in high IQ 
participants, A1-carriers (ANCOVA marginal mean=-0.070, SEM=0.049, 95\% CI=[-0.166, 0.027]) performed more poorly than A2 genotyped individuals (marginal mean $=0.044$, $\mathrm{SEM}=0.049,95 \% \mathrm{CI}=[-0.053,0.141])$.

The DRD2 ANKK1/Taq1A gene was thus not significantly or consistently implicated in WCST performance. These DRD2 findings are supported by Klaus and colleagues' (2019) meta-analysis of relevant studies, which similarly found that DRD2 C957T T-carriers possess better WCST performance, but did not find significant results for the ANKK1/Taq1A gene.

\section{Genetics of IQ}

As a robustness check, we found that IQ, as measured by Raven's SPM performance, was not associated with any dopaminergic genetic effect. Univariate ANCOVAs predicting IQ and controlling for age and gender, in the low IQ participant sample, were not significant for the three COMT genotypes (Met/Met, Val/Met, Val/Val; $\mathrm{F}(2,723)=0.107, \mathrm{p}=0.898)$, for the two COMT genotype groups (Met-carriers vs Val/Val; $\mathrm{F}(1,724)=0.104$, $\mathrm{p}=0.747$ ), for the three DRD2 C957T genotypes(T/T, T/C, C/C; $\mathrm{F}(2,723)=0.860, \mathrm{p}=0.424)$, or the two DRD2 genotypes $(\mathrm{T} / \mathrm{T}$ vs $\mathrm{C}$-carriers; $\mathrm{F}(1,724)=0.878, p=0.349)$. These patterns held when including WCST accuracy rate as a covariate - none of the dopaminergic genotype groups predicted Raven's performance, with or without cognitive flexibility, age, or gender, as covariates, $p$ s>.250. There were also no genetic effects on IQ in the whole participant sample, with or without covariates, $p \mathrm{~s}>.250$.

\section{COMT-DRD2 (C957T) Interactions}

Building on the findings in the low IQ participant group, which demonstrated that COMT genotype and C957T DRD2 genotype predict WCST performance, gene-gene interactions 
between COMT and DRD2 were investigated. As an initial check, we found that the genotypes are not correlated at $r=0.018, p=0.435$, which allows us to search for epistatic interactions. A univariate ANCOVA was computed on WCST accuracy rate, controlling for age and gender, and including both COMT genotype and C957T DRD2 genotype as fixed factor predictors. This revealed that both COMT $\mathrm{F}(1,478)=4.716, p=0.030$, Cohen's $\mathrm{d}=0.212$, and DRD2 genotype, $\mathrm{F}(1,478)=4.837, p=0.028$, Cohen's $\mathrm{d}=0.219$, were significant predictors when included simultaneously into the ANCOVA as fixed factors. To elucidate this further, participants were divided into four potential gene-gene genotype groupings according to whether they were Met-carriers or Val/Val genotyped on COMT, and whether they were T/T or C-carriers on DRD2. An ANCOVA on these four groups as the fixed factor variable, predicting WCST accuracy, revealed a significant effect, $\mathrm{F}(3,477)=4.024, p=0.008$ (see Table 3). As evident in Table 3 and Figure 2, there was a significant gene-gene interaction, with individuals genotyped as COMT Val/Val and DRD2 C-carriers performing most poorly on the WCST. Bonferroni-corrected post hoc comparisons demonstrated that the COMT Val/Val DRD2 C-carrier profile was significantly different to the COMT Met-carrier - DRD2 T/T profile $\left(\mathrm{M}_{\mathrm{diff}}=0.065, \mathrm{SE}=0.021, \mathrm{t}=3.008\right.$, Cohen's $\left.\mathrm{d}=0.418, \mathrm{p}_{\text {tukey }}=0.015, \mathrm{p}_{\text {bonf }}=0.017\right)$, the COMT Val/Val - DRD2 T/T profile $\left(M_{\text {diff }}=0.071, \mathrm{SE}=0.028, \mathrm{t}=2.569\right.$, Cohen's $\mathrm{d}=0.479$, $\left.p_{\text {tukey }}=0.051, p_{\text {bonf }}=0.063\right)$, and the COMT Met-carrier - DRD2 C-carrier profile $\left(M_{\text {diff }}=0.047\right.$, $\mathrm{SE}=0.017, \mathrm{t}=2.706$, Cohen's d=0.306, $\left.\mathrm{p}_{\text {tukey }}=0.035, \mathrm{p}_{\text {bonf }}=0.042\right)$.

As an additional robustness check to ensure that this analysis taps directly at flexibility and not general cognitive ability, the analysis was replicated on the residuals of WCST after accounting for IQ. ANCOVA with gender and age as covariates and the four COMT-DRD2 genotype groups as the predictor variable revealed a significant effect of genotype, $F(3,477)=3.753$, $p=0.011, \eta_{\mathrm{p}}^{2}=0.023$, thus corroborating the effect identified using WCST accuracy rate directly. 
Table 3. ANCOVA on WCST accuracy rate according to COMT-DRD2 C957T genotype in low IQ participants.

COMT-DRD2 Interaction (Low IQ)

\begin{tabular}{llllll}
\hline COMT-DRD2 Genotype & N & M & SEM & 95\% CI LB & 95\% CI UB \\
\hline COMT-Met, DRD2-TT & 91 & 0.660 & 0.016 & 0.629 & 0.690 \\
COMT-VV, DRD2-TT & 40 & 0.666 & 0.023 & 0.620 & 0.712 \\
COMT-Met, DRD2-Cs & 250 & 0.642 & 0.009 & 0.624 & 0.661 \\
COMT-VV, DRD2-Cs & 102 & 0.595 & 0.015 & 0.566 & 0.624 \\
& & & & & \\
\cline { 2 - 6 } & SS & $\mathbf{F}$ & $\mathbf{d f}$ & $\boldsymbol{p}$ & $\boldsymbol{\eta}_{\mathbf{p}}^{\mathbf{2}}$ \\
& 0.266 & 4.024 & 3,477 & 0.008 & 0.025
\end{tabular}

$\mathrm{M}=$ Marginal mean, controlling for age and gender. $\mathrm{SEM}=$ standard error of mean. $\mathrm{CI}=$ confidence interval. $\mathrm{LB}=\mathrm{lower}$ bound. UB=upper bound. SS=Type III Sum of Squares. Met=Met-carriers on COMT. VV=Val/Val on COMT. $\mathrm{TT}=\mathrm{T} / \mathrm{T}$ on DRD2 C957T. $\mathrm{Cs}=\mathrm{C}$-carriers on DRD2 C957T.

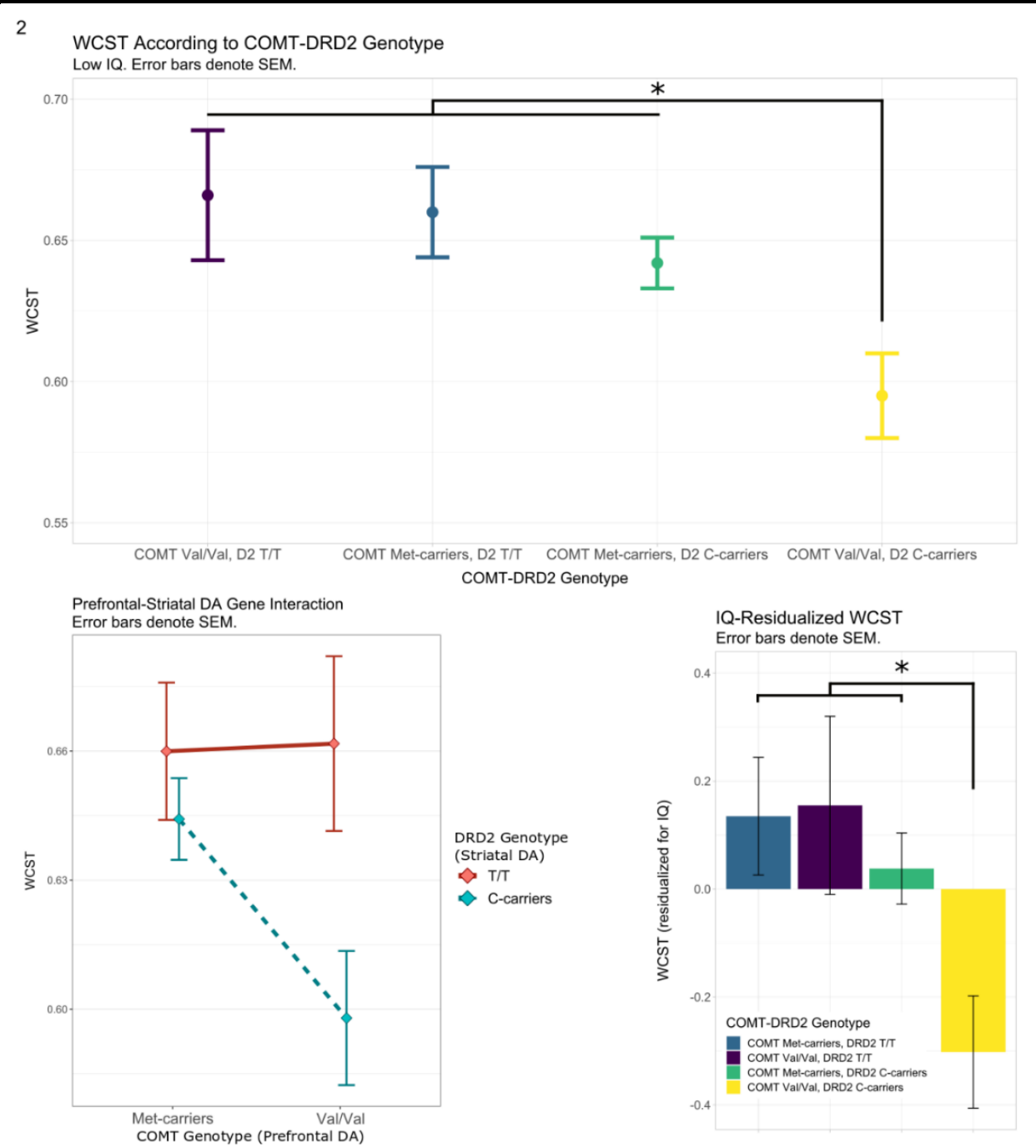

Figure 2. (A) WCST accuracy rate according to COMT-DRD2 C957T genotype, in low IQ participants, controlling for age and gender. (B) Interaction between COMT and DRD2 genotypes in predicting WCST accuracy rate. (C) IQ-residualized WCST according to COMTDRD2 C957T genotype, in low IQ participants, controlling for age and gender. *p $<.05$. 


\section{Discussion}

The present investigation sought to evaluate whether prefrontally-mediated dopamine genes (COMT) and striatally-concentrated D2 dopamine receptor genes (DRD2) are implicated in cognitive flexibility in humans, and how these may interact, in a well-powered large-scale analysis $(\mathrm{N}=1400)$. For the COMT gene, Met-carriers exhibit better performance than $\mathrm{Val} / \mathrm{Val}$ genotypes on the WCST (Figure 1), suggesting high prefrontal dopamine levels facilitate flexibility. For the DRD2 C957T gene, T/T genotypes had better performance than C-carriers (Figure 1), suggesting that high, striatally-concentrated D2 receptor availability - and thus presumably low striatal dopamine levels - promote mental flexibility. These genetic effects were only visible in low IQ individuals. Importantly, the results indicate epistatic gene-gene interactions, such that flexibility can emerge from either high dispositional PFC DA levels or low striatal DA levels (via high D2 receptor availability). Strikingly, individuals who are both Met-carriers on the COMT (which codes for high PFC DA) and T/T genotypes on the DRD2 (which codes for low striatal DA) do not have a significant flexibility advantage relative to individuals with the flexibility-advantageous alleles in only one of these systems. This pattern deviates from the additive expectation of allelic effects, thus reflecting genetic epistasis (Phillips, 2008). The equal flexibility manifest by possessing any combination of the flexibility-advantageous alleles in COMT or DRD2 reveals a plausible substitutability between dopamine systems: flexible cognition can emerge either through dispositionally high levels of DA in the PFC or dispositionally low levels of DA in the D2-rich striatum. In contrast, the presence of alleles coding for low DA in the PFC coupled with the presence of alleles coding for high DA in the D2-rich striatum contribute to cognitive rigidity - both low baseline PFC DA levels and high baseline striatal DA are necessary for rigidity and neither alone is sufficient (Figure 2). The results thereby uncover that low-IQ individuals with a Val/Val genotype on the 
COMT and C-carriers on the DRD2 gene reflect a genetic profile of particular vulnerability to rigid thought (Figure 2).

Theories of cognitive flexibility are incomplete if they situate the dopaminergic roots of adaptable behavior only in the prefrontal cortex or only in the striatum, or presuppose a complete dissociability; the genetic epistasis identified here suggests that either system can facilitate flexibility. Dispositionally high prefrontal dopamine levels can compensate when dispositional striatal dopamine levels are also high, and low dispositional striatal DA can compensate when PFC DA is low. The effect of COMT alleles on cognitive flexibility is dependent on the DRD2 genetic context, and vice versa, suggesting that dopaminergic genetic effects underpinning flexible behavior are co-dependent and contextually-mediated. Given that these patterns persisted when intelligence scores were partialled out of the cognitive flexibility score, these findings indicate a specific role for dopamine in cognitive flexibility, which is not reducible simply to cognitive ability. Notably, for individuals with average and high IQ, dopamine genetic dispositions do not result in pronounced differences in cognitive flexibility.

The findings highlight two critical interactions that underpin the genetic basis of flexible cognition: (1) interactions between cognitive systems and (2) interactions between genetically modulated dopamine systems. Firstly, since the relationship between dopaminergic gene dispositions and cognitive flexibility was only apparent for individuals with low IQ, high cognitive ability can mask these dopaminergic genetic effects while low cognitive ability brings these genetic influences to the fore. These findings may imply that the meta-analytic contradictions manifest in previous studies (e.g. Barnett, Jones, Robbins, \& Muller, 2007; Barnett, Scoriel, \& Munafo, 2008; Flint \& Munafo, 2006; Mier, Kiursch, \& Meyer-Lindenberg, 2010) could be rooted in variation in the samples' baseline level of cognitive ability. Moreover, the moderating role of cognitive ability is consistent with a prominent literature depicting that baseline working memory frequently interacts with DA pharmacological manipulations (Cools 
et al., 2008, 2009; Cools \& D’Esposito, 2011; Frank \& Fosella, 2011; Frank \& O'Reilly, 2006; Soutschek et al., 2020). This line of research illustrates that individuals with high versus low working memory can respond differentially to DA pharmacological interventions (Cohen, Krohn-Grimberghe, Elger, \& Weber, 2007; Gibbs \& D’Esposito, 2006; Kimberg \& D’Esposito, 2003; Cools \& D'Esposito, 2011; van Holstein et al., 2011), and posits that an optimal level of dopamine is required for cognitive functioning. Insufficient or excessive dopamine levels can degrade performance, and the optimal dopamine level depends on individual differences and task requirements (Cools, Sheridan, Jacobs, \& D’Esposito, 2007).

The second interaction reflected the epistatic, compensatory interaction between prefrontally-mediated genes and striatally-concentrated D2 receptor genes, which suggests that there is some form of redundancy in dopaminergic neurotransmission. Possessing either a COMT Met-allele or a DRD2 T/T genotype is sufficient for high cognitive flexibility in low IQ participants, while having both the COMT and DRD2 flexibility-advantage genotypes does not confer an additional advantage on the WCST. On the other hand, cognitive rigidity requires both low prefrontal DA and high striatal DA. It must not be ignored that although D2 receptors are predominantly expressed in the striatum, they are also located in the PFC (Goldman-Rakic et al., 1990; Floresco, 2013) and the COMT-D2DR synergy could also occur there. Lumme and colleagues (2007) found that greater D2 receptor density binding - and presumably a decrease in dopaminergic activity - in the right anterior cingulate cortex was linked to poorer WCST performance, implicating cortical D2 receptors (and their effect on general dopaminergic activity), and not only striatal D2 receptors, in WCST performance. These findings are consistent with the present study. Indeed, several lines of research on behavioral flexibility highlight the interconnections between the dopamine functions of the PFC and striatum (Meyer-Lindenberg et al., 2002), demonstrating that striatal D2 receptors can impact dopamine functioning and D1 receptor activation in the PFC (Kellendonk et al., 2006). 
Moreover, a growing emphasis on functional connectivity has illustrated that cognitive flexibility is associated with functional connectivity between striatal and prefrontal regions (Morris, Kundu, et al., 2015; Vaghi et al., 2017). Stelzel and colleagues (2010, 2013) have shown how a D2 agonist such as bromocriptine can enhance fronto-striatal functional connectivity in flexible human performance, indicating an important role for the D2 receptor. Functionally, rising dopamine levels in the striatum tend to be linked to decreases in dopamine levels in the prefrontal cortex, and vice versa (Akil et al., 2003; Meyer-Lindenberg et al., 2005), and so it is interesting that the prefrontal-striatal DA reciprocal relations echo the high striatal DA coupled with low prefrontal DA that was found here to underpin mental rigidity.

These findings speak to theories on the neurochemical reciprocity between dopamine in the prefrontal cortex and dopamine in the striatum (Cools, 2016; Roberts et al., 1994; MeyerLindenberg et al., 2002), as well as to accounts that highlight how dopaminergic drugs can have opposing effects depending on clinical condition, baseline dopamine levels or baseline working memory (e.g. Broadway, Frank, \& Cavanagh, 2019; Cherkasova et al., 2017; Cools, 2019; Cools, Frank, Gibbs, Miyakawa, Jagust, \& D’Esposito, 2009; Cools \& D’Esposito, 2011; Frank \& O’Reilly, 2006; Frobose et al., 2020; Kim et al., 2018; Samanez-Larkin et al., 2013). In particular, the epistatic gene-gene interaction adds nuance to theories that postulate a dissociability between striatal and prefrontal dopamine action in shaping flexibility (Doll, Bath, Daw, \& Frank, 2016). Several lines of research in the study of cognitive flexibility, working memory, and dopamine have led to the hypothesis that striatal D2-mediated dopamine governs flexibility while prefrontal dopamine underpins working memory and cognitive stability (Boot, Baas, van Gaal, Cools, \& De Dreu, 2017). As such, stimulating D1-type receptors, which are the most abundant DA receptor type in the PFC (Lidow et al., 1991), enhances cognitive control and working memory (Durstewitz \& Seamans, 2008; Vijayraghavan et al., 2007), and stimulating D2-type receptors, which are prevalent in the striatum (Camps et al., 1989), 
facilitates flexibility (Dodds et al., 2009; Mehta et al., 2004). Note however in rodents that blocking PFC D1 and D2 receptors locally both impaired set-shifting, although there were no effects of D1 or D2 agonists, even at high doses. By contrast, blockade of the D2-like D4 receptor improved set-shifting whereas a D4 receptor agonist impaired it (Floresco 2013). D4 receptor polymorphisms have been related to novelty seeking in humans (Ebstein et al 1996 ) but have not yet been studied in this set-shifting context.

In line with the proposal that dopamine modulates cognitive control and cognitive flexibility in an inverted-U shaped fashion (Cools \& Robbins, 2004; Cools \& D’Esposito, 2011), overstimulating the prefrontal-rich D1 receptors has been shown to lead to excessive cognitive control in the form of rigidity (Durstewitz \& Seamans, 2008; Vijayraghavan et al., 2007) and overstimulating the striatally-concentrated D2 receptors leads to distractibility (Durstewitz \& Seamans, 2008; Kellendonk et al., 2006). This theory, and associated experiments, would thus predict that the COMT Met genotype facilitates enhanced working memory, whereas the Val genotype promotes cognitive flexibility (Bilder, Volavka, Lachman, \& Grace, 2004; Chrysikou, Weber, \& Thompson-Schill, 2014; Colzato et al., 2010, 2014; Nolan, Bilder, Lachman, Volavka, 2004; Zabelina et al., 2015). The present results diverge from this prediction, as adaptability on the Wisconsin Card Sorting Test required either high dispositional PFC dopamine levels or low dispositional striatal dopamine levels, and in fact dispositionally low prefrontal dopamine and high striatal dopamine were marks of rigidity, not flexibility, on the WCST.

Reconciling the present findings with the literature positing that striatal dopamine underpins flexibility while prefrontal dopamine governs persistence and stability involves addressing the complexity of flexible behavior as it is typically executed in human everyday life and measured in the WCST - a task that requires adaptability but also maintenance of goals and reward structures in mind (Klanker, Feenstra, \& Denys, 2013). Recent endeavors using 
biophysically realistic computational models suggest that the relationship between DA, PFC neurons, and flexible behavior may occur through two types of network dynamics (Durstewitz \& Seamans, 2008): changes mediated by D1 receptors and those mediated by D2 receptors. While the D1-state facilitates stable and distractor-resilient mental representations, due to a high energy barrier between different networks states in D1-dominated regimes, the D2regimes lead to states in which noise can more easily and spontaneously modulate representations. D1-regimes are thought to facilitate cognitive stability while D2-regimes enable flexibility. Hence, according to the Dual-State Theory of PFC DA function (Durstewitz \& Seamans, 2008), the impact of dopamine on cognitive function is intertwined with the stimulated DA receptor class (D1 vs D2). Considering COMT genotypes and cognitive flexibility, Durstwitz and Seamans (2008) theorize that Val/Val and Met/Met genotypes are related to different baseline D1/D2 activation ratios, and respond differently to challenges requiring adaptability or high cognitive load. In the context of the WCST, Durstewitz and Seamans (2008) hypothesize that "given the multidimensional nature of the task, it is... conceivable that poor performance on the WCST could emerge as a result of a dysregulation of either the D1-state or the D2-state" (p. 745). The present results could suggest that the dopamine dysregulation that leads to cognitive rigidity may implicate both D1- and D2-states (see also Lumme et al., 2007), depending on individuals' baseline abilities and their genetic profiles.

Cognitive flexibility is a multifaceted construct that is likely to be constituted of component parts, including attentional set-shifting, strategy shifting, reversal learning, task switching, and generative flexibility marked by creative ideation. This diversity is indeed clear in the multitude of psychiatric conditions that are characterized by rigidity, where rigidity can be manifest through compulsivity (as in OCD; Meiran, Diamond, Toder, \& Nemets, 2011; Ramakrishan, Robbins, \& Zmigrod, under review), perseverative thoughts (in anxiety 
disorders; Ottaviani et al., 2016), inflexible delusions (as in schizophrenia; Diaconescu et al., 2020; Mosiolek et al., 2016), or distress in the face of change or perceptual overstability (as in autism; Poljac, Hoofs, Princen, Poljac, 2017; Watanabe, Lawson, Wallden, \& Rees, 2019). It is therefore plausible that the kind of dopamine dysregulation that produces cognitive rigidity on the WCST, which reflects a reactive inflexibility in the face of changing rules and reward contingencies, differs from the dopamine dysregulation that might generate rigidity in taskswitching paradigms that do not involve rewards (Stelzel et al., 2010). Mapping out the dopaminergic characteristics of different facets of flexibility - while appreciating that there will be both overlaps and discrepancies in their neurocognitive antecedents - will be a valued step for the field.

Open questions remain regarding the precise mechanism by which IQ moderates the relationship between flexibility and dopamine. Theorists have previously assumed that low working memory is linked to low prefrontal dopamine, and that this explains the moderating effect of baseline working memory on the cognitive impact of dopaminergic drugs. However, in the present sample, we did not find that IQ was linked to differences in COMT or DRD2 genotype. In order to understand why, neurobiologically, moderate to high IQ eliminates the genetic effects on flexibility, future research will need to shed further light on the functional and structural neural mechanisms that govern interactions between cognitive ability and cognitive flexibility (Zmigrod et al., 2019).

Elucidating the genetics of cognitive flexibility has significant implications along several clinical, societal, and scientific dimensions. Firstly, it is of importance to the National Institute of Mental Health's research domain criteria (RDoC) initiative, which sets out to develop biologically-informed cognitive constructs. By corroborating the role of specific genes in cognitive control and by identifying gene-gene interactions and functionally defined networks of genes, this line of research can contribute to better comprehending the aetiology 
of psychopathology (Bowirrat et al., 2012; Glahn, Knowles, \& Pearlson, 2016). Several psychiatric conditions sit at the intersection of dopaminergic abnormalities and rigid behavior or aberrant cognitive control, including Parkinson's disease attention deficit hyperactivity disorder, addiction, obsessive-compulsive disorder, and others. Dopamine dysfunction in the PFC and striatum has been shown to shape schizophrenia in particular (Durstewitz \& Seamans, 2008; Simpson, Kellendonk, \& Kandel, 2010). Defining the dopaminergic basis of inflexible behavior is therefore critical for advancing psychopharmacological research and for understanding paradoxical or personalized treatment effects (Cools, 2019; Durstewitz \& Seamans, 2008) as well as the effects of stress (Diamond, 2011; Zareyan et al., 2021). The implications of our observations are that the cognitive enhancing effects of dopaminergic agonists will be most prominent in individuals with low IQ, or presumably also, low working memory capacity. Secondly, clarifying the neurobiology of flexible behavior gives a more biological framework for research demonstrating relationships between cognitive flexibility on the WCST and socio-political behavior (for review see: Zmigrod, 2020; Zmigrod, Rentfrow, \& Robbins, 2018, 2019, 2020; Zmigrod et al., 2019, 2021), indicating that dopamine genes may shape proclivities not only for cognitive rigidity but for ideological rigidity and dogmatism too. The compensatory epistatic interaction identified here may also offer tentative clues regarding the evolution of behavioral plasticity. As Phillips (2008) notes in their review of the genetics literature, "epistasis arises as a natural by-product of the evolutionary process" and "there is clear evidence that epistasis helps to structure the possible pathways that evolution can follow". If prefrontal and striatal systems can compensate for each other, and rigidity only emerges when both systems are characterized by the rigidity-leaning dopaminergic characteristics, this is suggestive of a biological tendency towards facilitating flexibility. Lastly, these findings are important to neurocognitive and computational approaches aimed at unpacking how dopamine neurotransmission gives rise to cognitive control, creativity, and 
reinforcement learning (Boot et al., 2017; Floresco, 2013; Niv, Daw, Joel, \& Dayan, 2007; Sharpe et al., 2017, 2020; Uddin, 2021; Ueltzhoffer et al., 2015). Recent research suggests that COMT and DRD2 C957T interact through genetic influences on brain structure in cortical regions (Miranda, Rodrigue, \& Kennedy, 2020), and so jointly associating genes, cognition, and brain structure may be the next frontier in the understanding the granular mechanisms underpinning cognitive flexibility. 


\section{References}

Apud, J. A., Mattay, V., Chen, J., Kolachana, B. S., Callicott, J. H., Rasetti, R., ... \& Goldberg, T. E. (2007). Tolcapone improves cognition and cortical information processing in normal human subjects. Neuropsychopharmacology, 32(5), 1011-1020.

Barnett, J. H., Jones, P. B., Robbins, T. W., \& Müller, U. (2007). Effects of the catechol- O methyltransferase Val 158 Met polymorphism on executive function: A meta-analysis of the Wisconsin Card Sort Test in schizophrenia and healthy controls. Molecular Psychiatry, 12(5), 502-509. https://doi.org/10.1038/sj.mp.4001973

Barnett, Jennifer H., Scoriels, L., \& Munafò, M. R. (2008). Meta-Analysis of the Cognitive Effects of the Catechol-O-Methyltransferase Gene Val158/108Met Polymorphism. Biological Psychiatry, 64(2), 137-144. https://doi.org/10.1016/j.biopsych.2008.01.005

Barnett, Jennifer H., Scoriels, L., \& Munafò, M. R. (2011). Reply to: With Great Power Comes Great Responsibility: Meta-Analytic Proof for a Timeless Insight. Biological Psychiatry, 69(10), e39. https://doi.org/10.1016/j.biopsych.2010.11.028

Berryhill, M. E., Wiener, M., Stephens, J. A., Lohoff, F. W., \& Coslett, H. B. (2013). COMT and ANKK1-Taq-Ia genetic polymorphisms influence visual working memory. PloS one, 8(1), e55862.

Bestmann, S., Ruge, D., Rothwell, J., \& Galea, J. M. (2014). The Role of Dopamine in Motor Flexibility. Journal of Cognitive Neuroscience, 27(2), 365-376. https://doi.org/10.1162/jocn_a_00706

Bilker, W. B., Hansen, J. A., Brensinger, C. M., Richard, J., Gur, R. E., \& Gur, R. C. (2012). Development of abbreviated nine-item forms of the Raven's standard progressive matrices test. Assessment, 19(3), 354-369.

Bolton, J. L., Marioni, R. E., Deary, I. J., Harris, S. E., Stewart, M. C., Murray, G. D., Fowkes, F. G. R., \& Price, J. F. (2010). Association Between Polymorphisms of the Dopamine Receptor D2 and Catechol-o-Methyl Transferase Genes and Cognitive Function. Behavior Genetics, 40(5), 630-638. https://doi.org/10.1007/s10519-010-9372-y

Boot, N., Baas, M., van Gaal, S., Cools, R., \& De Dreu, C. K. W. (2017). Creative cognition and dopaminergic modulation of fronto-striatal networks: Integrative review and research 
agenda. Neuroscience \& Biobehavioral Reviews, 78, 13-23. https://doi.org/10.1016/j.neubiorev.2017.04.007

Boulougouris, V., Castañé, A., \& Robbins, T. W. (2009). Dopamine D2/D3 receptor agonist quinpirole impairs spatial reversal learning in rats: investigation of D3 receptor involvement in persistent behavior. Psychopharmacology, 202(4), 611-620.

Boureau, Y.-L., \& Dayan, P. (2011). Opponency Revisited: Competition and Cooperation Between Dopamine and Serotonin. Neuropsychopharmacology, 36(1), 74-97. https://doi.org/10.1038/npp.2010.151

Bowirrat, A., Chen, T. J. H., Oscar-Berman, M., Madigan, M., Chen, A. L., Bailey, J. A., Braverman, E. R., Kerner, M., Giordano, J., Morse, S., Downs, B. W., Waite, R. L., Fornari, F., Armaly, Z., \& Blum, K. (2012). Neuropsychopharmacology and Neurogenetic Aspects of Executive Functioning: Should Reward Gene Polymorphisms Constitute a Diagnostic Tool to Identify Individuals at Risk for Impaired Judgment? Molecular Neurobiology, 45(2), 298-313. https://doi.org/10.1007/s12035-012-8247-z

Bowirrat, A., \& Oscar-Berman, M. (2005). Relationship between dopaminergic neurotransmission, alcoholism, and reward deficiency syndrome. American Journal of Medical Genetics Part B: Neuropsychiatric Genetics, 132(1), 29-37.

Broadway, J. M., Frank, M. J., \& Cavanagh, J. F. (2018). Dopamine D2 agonist affects visuospatial working memory distractor interference depending on individual differences in baseline working memory span. Cognitive, Affective, \& Behavioral Neuroscience, 18(3), 509520. https://doi.org/10.3758/s13415-018-0584-6

Castañé, A., Theobald, D. E., \& Robbins, T. W. (2010). Selective lesions of the dorsomedial striatum impair serial spatial reversal learning in rats. Behavioural brain research, 210(1), 7483.

Chamberlain, S. R., Fineberg, N. A., Menzies, L. A., Blackwell, A. D., Bullmore, E. T., Robbins, T. W., \& Sahakian, B. J. (2007). Impaired cognitive flexibility and motor inhibition in unaffected first-degree relatives of patients with obsessive-compulsive disorder. American Journal of Psychiatry, 164(2), 335-338.

Chamberlain, S. R., Solly, J. E., Hook, R. W., Vaghi, M. M., \& Robbins, T. W. (2021). Cognitive Inflexibility in OCD and Related Disorders. Current topics in behavioral 
neurosciences, 10.1007/7854_2020_198. Advance online publication. https://doi.org/10.1007/7854_2020_198

Chen, J., Lipska, B. K., Halim, N., Ma, Q. D., Matsumoto, M., Melhem, S., ... \& Egan, M. F. (2004). Functional analysis of genetic variation in catechol-O-methyltransferase (COMT): effects on mRNA, protein, and enzyme activity in postmortem human brain. The American Journal of Human Genetics, 75(5), 807-821.

Cherkasova, M. V., Faridi, N., Casey, K. F., Larcher, K., O’Driscoll, G. A., Hechtman, L., Joober, R., Baker, G. B., Palmer, J., Evans, A. C., Dagher, A., Benkelfat, C., \& Leyton, M. (2017). Differential Associations between Cortical Thickness and Striatal Dopamine in Treatment-Naïve Adults with ADHD vs. Healthy Controls. Frontiers in Human Neuroscience, 11. https://doi.org/10.3389/fnhum.2017.00421

Clarke, H. F., Hill, G. J., Robbins, T. W., \& Roberts, A. C. (2011). Dopamine, But Not Serotonin, Regulates Reversal Learning in the Marmoset Caudate Nucleus. Journal of Neuroscience, 31(11), 4290-4297. https://doi.org/10.1523/JNEUROSCI.5066-10.2011

Clarke, H. F., Robbins, T. W., \& Roberts, A. C. (2008). Lesions of the medial striatum in monkeys produce perseverative impairments during reversal learning similar to those produced by lesions of the orbitofrontal cortex. Journal of Neuroscience, 28(43), 10972-10982.

Cohen, M. X., Krohn-Grimberghe, A., Elger, C. E., \& Weber, B. (2007). Dopamine gene predicts the brain's response to dopaminergic drug. European Journal of Neuroscience, 26(12), 3652-3660. https://doi.org/10.1111/j.1460-9568.2007.05947.x

Comings, D. E., Rosenthal, R. J., Lesieur, H. R., Rugle, L. J., Muhleman, D., Chiu, C., ... \& Gade, R. (1996). A study of the dopamine D2 receptor gene in pathological gambling. Pharmacogenetics, 6(3), 223-234.

Cools, R., Frank, M. J., Gibbs, S. E., Miyakawa, A., Jagust, W., \& D’Esposito, M. (2009). Striatal Dopamine Predicts Outcome-Specific Reversal Learning and Its Sensitivity to Dopaminergic Drug Administration. Journal of Neuroscience, 29(5), 1538-1543. https://doi.org/10.1523/JNEUROSCI.4467-08.2009

Cools, R., Gibbs, S. E., Miyakawa, A., Jagust, W., \& D’Esposito, M. (2008). Working Memory Capacity Predicts Dopamine Synthesis Capacity in the Human Striatum. Journal of Neuroscience, 28(5), 1208-1212. https://doi.org/10.1523/JNEUROSCI.4475-07.2008 
Cools, R. (2015). The cost of dopamine for dynamic cognitive control. Current Opinion in Behavioral Sciences, 4, 152-159. https://doi.org/10.1016/j.cobeha.2015.05.007

Cools, R. (2016). The costs and benefits of brain dopamine for cognitive control. WIREs Cognitive Science, 7(5), 317-329. https://doi.org/10.1002/wcs.1401

Cools, R. (2019). Chemistry of the Adaptive Mind: Lessons from Dopamine. Neuron, 104(1), 113-131. https://doi.org/10.1016/j.neuron.2019.09.035

Cools, R., Barker, R. A., Sahakian, B. J., \& Robbins, T. W. (2003). L-Dopa medication remediates cognitive inflexibility, but increases impulsivity in patients with Parkinson's disease. Neuropsychologia, 41(11), 1431-1441. $\quad$ https://doi.org/10.1016/S0028$\underline{3932(03) 00117-9}$

Cools, R., \& D’Esposito, M. (2011). Inverted-U-Shaped Dopamine Actions on Human Working Memory and Cognitive Control. Biological Psychiatry, 69(12), e113-e125. https://doi.org/10.1016/j.biopsych.2011.03.028

Cools, R., \& Robbins, T. W. (2004). Chemistry of the adaptive mind. Philosophical Transactions of the Royal Society of London. Series A: Mathematical, Physical and Engineering Sciences, 362(1825), 2871-2888.

Cools, R., Sheridan, M., Jacobs, E., \& D'Esposito, M. (2007). Impulsive personality predicts dopamine-dependent changes in frontostriatal activity during component processes of working memory. Journal of Neuroscience, 27(20), 5506-5514.

Diaconescu, A. O., Wellstein, K. V., Kasper, L., Mathys, C., \& Stephan, K. E. (2020). Hierarchical Bayesian models of social inference for probing persecutory delusional ideation. Journal of Abnormal Psychology, 129(6), 556.

Diamond, A. (2011). Biological and social influences on cognitive control processes dependent on prefrontal cortex. Progress in brain research, 189, 319-339.

Diamond, A., Briand, L., Fossella, J., \& Gehlbach, L. (2004). Genetic and neurochemical modulation of prefrontal cognitive functions in children. American Journal of Psychiatry, 161(1), 125-132.

Divac, I., Rosvold, H. E., \& Szwarcbart, M. K. (1967). Behavioral effects of selective ablation of the caudate nucleus. Journal of comparative and physiological psychology, 63(2), 184. 
Doll, B. B., Hutchison, K. E., \& Frank, M. J. (2011). Dopaminergic Genes Predict Individual Differences in Susceptibility to Confirmation Bias. Journal of Neuroscience, 31(16), 61886198. https://doi.org/10.1523/JNEUROSCI.6486-10.2011

Domingo, J., Baeza-Centurion, P., \& Lehner, B. (2019). The causes and consequences of genetic interactions (epistasis). Annual review of genomics and human genetics, 20, 433-460.

Durstewitz, D., \& Seamans, J. K. (2008). The Dual-State Theory of Prefrontal Cortex Dopamine Function with Relevance to Catechol-O-Methyltransferase Genotypes and $\begin{array}{llll}\text { Schizophrenia. } & \text { Biological } & \text { 739-749. }\end{array}$ https://doi.org/10.1016/j.biopsych.2008.05.015

Ebstein, R. P., Novick, O., Umansky, R., Priel, B., Osher, Y., Blaine, D., ... \& Belmaker, R. H. (1996). Dopamine D4 receptor (D4DR) exon III polymorphism associated with the human personality trait of novelty seeking. Nature genetics, 12(1), 78-80.

Egan, M. F., Goldberg, T. E., Kolachana, B. S., Callicott, J. H., Mazzanti, C. M., Straub, R. E., Goldman, D., \& Weinberger, D. R. (2001). Effect of COMT Val108/158 Met genotype on frontal lobe function and risk for schizophrenia. Proceedings of the National Academy of Sciences, 98(12), 6917-6922. https://doi.org/10.1073/pnas.111134598

Ersche, K.D., Rosier, J.P., Robbins, T.W. \& Sahakian, B.J. (2008) Chronic cocaine but not chronic amphetamine use is associated with perseverative responding in humans. Psychopharmacology, 197, 421- 431.

Ersche, K. D., Roiser, J. P., Abbott, S., Craig, K. J., Müller, U., Suckling, J., ... \& Fineberg, N. A. (2011). Response perseveration in stimulant dependence is associated with striatal dysfunction and can be ameliorated by a D2/3 receptor agonist. Biological psychiatry, 70(8), 754-762.

Figee, M., Pattij, T., Willuhn, I., Luigjes, J., van den Brink, W., Goudriaan, A., ... \& Denys, D. (2016). Compulsivity in obsessive-compulsive disorder and addictions. European Neuropsychopharmacology, 26(5), 856-868.

Flint, J., \& Munafò, M. R. (2007). The endophenotype concept in psychiatric genetics. Psychological Medicine, 37(2), 163-180. https://doi.org/10.1017/S0033291706008750 
Floresco, S. B. (2013). Prefrontal dopamine and behavioral flexibility: Shifting from an "inverted-U" toward a family of functions. Frontiers in Neuroscience, 7. https://doi.org/10.3389/fnins.2013.00062

Frank, M. J., Doll, B. B., Oas-Terpstra, J., \& Moreno, F. (2009). Prefrontal and striatal dopaminergic genes predict individual differences in exploration and exploitation. Nature neuroscience, 12(8), 1062.

Frank, M. J., \& Hutchison, K. (2009). Genetic contributions to avoidance-based decisions: Striatal D2 receptor polymorphisms. Neuroscience, 164(1), 131-140. https://doi.org/10.1016/j.neuroscience.2009.04.048

Frank, M. J. \& Fossella, J. A. (2011). Neurogenetics and Pharmacology of Learning, Motivation, and Cognition. Neuropsychopharmacology, 36(1), 133-152. https://doi.org/10.1038/npp.2010.96

Frank, M. J., Moustafa, A. A., Haughey, H. M., Curran, T., \& Hutchison, K. E. (2007). Genetic triple dissociation reveals multiple roles for dopamine in reinforcement learning. Proceedings of the National Academy of Sciences, 104(41), 16311-16316.

Frank, M.J., \& O'Reilly, R. C. (2006). A mechanistic account of striatal dopamine function in human cognition: Psychopharmacological studies with cabergoline and haloperidol. Behavioral Neuroscience, 120(3), 497-517. https://doi.org/10.1037/0735-7044.120.3.497

Garcia-Garcia, M., Barceló, F., Clemente, I. C., \& Escera, C. (2010). The role of the dopamine transporter DAT1 genotype on the neural correlates of cognitive flexibility. European Journal of Neuroscience, 31(4), 754-760. https://doi.org/10.1111/j.1460-9568.2010.07102.x

Garcia-Garcia, M., Via, M., Zarnowiec, K., SanMiguel, I., Escera, C., \& Clemente, I. C. (2017). COMT and DRD2/ANKK-1 gene-gene interaction account for resetting of gamma neural oscillations to auditory stimulus-driven attention. PLOS ONE, 12(2), e0172362. https://doi.org/10.1371/journal.pone.0172362

Gibbs, S. E. B., \& D’Esposito, M. (2006). A functional magnetic resonance imaging study of the effects of pergolide, a dopamine receptor agonist, on component processes of working memory. Neuroscience, 139(1), 359-371.

Glahn, D. C., Knowles, E. E. M., \& Pearlson, G. D. (2016). Genetics of cognitive control: Implications for Nimh's research domain criteria initiative. American Journal of Medical 
Genetics Part B: Neuropsychiatric Genetics, 171(1), 111-120. https://doi.org/10.1002/ajmg.b.32345

Gluskin, B. S., \& Mickey, B. J. (2016). Genetic variation and dopamine D2 receptor availability: a systematic review and meta-analysis of human in vivo molecular imaging studies. Translational psychiatry, 6(3), e747-e747.

Goldman, D., Weinberger, D. R., Malhotra, A. K., \& Goldberg, T. E. (2009). The Role of COMT Val158Met in Cognition. Biological Psychiatry, 65(1), e1-e2. https://doi.org/10.1016/j.biopsych.2008.07.032

Goldman-Rakic, P. S., Lidow, M. S., \& Gallager, D. W. (1990). Overlap of dopaminergic, adrenergic, and serotoninergic receptors and complementarity of their subtypes in primate prefrontal cortex. Journal of Neuroscience, 10(7), 2125-2138.

Goldman-Rakic, P. S. (1995). Cellular basis of working memory. Neuron, 14(3), 477-485.

Hagelberg, N., Jääskeläinen, S. K., Martikainen, I. K., Mansikka, H., Forssell, H., Scheinin, H., ... \& Pertovaara, A. (2004). Striatal dopamine D2 receptors in modulation of pain in humans: a review. European journal of pharmacology, 500(1-3), 187-192.

Heaton, R. K. (1981). Wisconsin Card Sorting Test manual. Odessa, FL: Psychological

Hirvonen, M., Laakso, A., Någren, K., Rinne, J. O., Pohjalainen, T., \& Hietala, J. (2004). C957T polymorphism of the dopamine D2 receptor (DRD2) gene affects striatal DRD2 availability in vivo. Molecular Psychiatry, 9(12), 1060-1061. https://doi.org/10.1038/sj.mp.4001561

Hirvonen, M. M., Laakso, A., Någren, K., Rinne, J. O., Pohjalainen, T., \& Hietala, J. (2009). C957T polymorphism of dopamine D2 receptor gene affects striatal DRD2 in vivo availability by changing the receptor affinity. Synapse, 63(10), 907-912. https://doi.org/10.1002/syn.20672

Hirvonen, M. M., Lumme, V., Hirvonen, J., Pesonen, U., Någren, K., Vahlberg, T., Scheinin, H., \& Hietala, J. (2009). C957T polymorphism of the human dopamine D2 receptor gene predicts extrastriatal dopamine receptor availability in vivo. Progress in NeuroPsychopharmacology and Biological Psychiatry, 33(4), 630-636. https://doi.org/10.1016/j.pnpbp.2009.02.021 
Horst, N. K., Jupp, B., Roberts, A. C., \& Robbins, T. W. (2019). D2 receptors and cognitive flexibility in marmosets: Tri-phasic dose-response effects of intra-striatal quinpirole on serial reversal performance. Neuropsychopharmacology, 44(3), 564-571. https://doi.org/10.1038/s41386-018-0272-9

Jocham, G., Klein, T. A., Neumann, J., Cramon, D. Y. von, Reuter, M., \& Ullsperger, M. (2009). Dopamine DRD2 Polymorphism Alters Reversal Learning and Associated Neural Activity. Journal of Neuroscience, 29(12), 3695-3704. https://doi.org/10.1523/JNEUROSCI.5195-08.2009

Kehagia, A. A., Murray, G. K., \& Robbins, T. W. (2010). Learning and cognitive flexibility: frontostriatal function and monoaminergic modulation. Current opinion in neurobiology, 20(2), 199-204.

Kellendonk, C., Simpson, E. H., Polan, H. J., Malleret, G., Vronskaya, S., Winiger, V., ... \& Kandel, E. R. (2006). Transient and selective overexpression of dopamine D2 receptors in the striatum causes persistent abnormalities in prefrontal cortex functioning. Neuron, 49(4), 603615.

Kim, J., Zhang, K., Cai, W., YorkWilliams, S., Ua Cruadhlaoich, M. A. I., Llanes, S., Menon, V., \& Poston, K. L. (2018). Dopamine-related dissociation of cortical and subcortical brain activations in cognitively unimpaired Parkinson's disease patients OFF and ON medications. Neuropsychologia, 119, 24-33. https://doi.org/10.1016/j.neuropsychologia.2018.07.024

Kimberg, D. Y., \& D'Esposito, M. (2003). Cognitive effects of the dopamine receptor agonist pergolide. Neuropsychologia, 41(8), 1020-1027.

Kirkby, R. J. (1969). Caudate nucleus lesions and perseverative behavior. Physiology \& Behavior, 4(4), 451-454.

Klanker, M., Feenstra, M., \& Denys, D. (2013). Dopaminergic control of cognitive flexibility in humans and animals. Frontiers in neuroscience, 7, 201.

Klaus, K., Butler, K., Curtis, F., Bridle, C., \& Pennington, K. (2019). The effect of ANKK1 Taq1A and DRD2 C957T polymorphisms on executive function: A systematic review and meta-analysis. Neuroscience \& Biobehavioral Reviews, 100, 224-236. https://doi.org/10.1016/j.neubiorev.2019.01.021 
Klaus, K., Butler, K., Durrant, S. J., Ali, M., Inglehearn, C. F., Hodgson, T. L., Gutierrez, H., \& Pennington, K. (2017). The effect of COMT Val158Met and DRD2 C957T polymorphisms on executive function and the impact of early life stress. Brain and Behavior, 7(5), e00695. https://doi.org/10.1002/brb3.695

Klein, T. A., Neumann, J., Reuter, M., Hennig, J., von Cramon, D. Y., \& Ullsperger, M. (2007). Genetically determined differences in learning from errors. Science, 318(5856), 1642-1645.

Lachman, H. M., Papolos, D. F., Saito, T., Yu, Y. M., Szumlanski, C. L., \& Weinshilboum, R. M. (1996). Human catechol-O-methyltransferase pharmacogenetics: description of a functional polymorphism and its potential application to neuropsychiatric disorders. Pharmacogenetics and Genomics, 6(3), 243-250.

Laruelle, M. (2000). Imaging synaptic neurotransmission with in vivo binding competition techniques: a critical review. Journal of Cerebral Blood Flow \& Metabolism, 20(3), 423-451.

Lee, B., Groman, S., London, E. D., \& Jentsch, J. D. (2007). Dopamine D 2/D 3 receptors play a specific role in the reversal of a learned visual discrimination in monkeys. Neuropsychopharmacology, 32(10), 2125-2134.

Lidow, M. S., Goldman-Rakic, P. S., Rakic, P., \& Innis, R. B. (1989). Dopamine D2 receptors in the cerebral cortex: distribution and pharmacological characterization with $[3 \mathrm{H}]$ raclopride. Proceedings of the National Academy of Sciences, 86(16), 6412-6416.

Lidow, M. S., Goldman-Rakic, P. S., Gallager, D. W., \& Rakic, P. (1991). Distribution of dopaminergic receptors in the primate cerebral cortex: quantitative autoradiographic analysis using $[3 \mathrm{H}]$ raclopride, $[3 \mathrm{H}]$ spiperone and [3H] SCH23390. Neuroscience, 40(3), 657-671.

Lindgren, H. S., Wickens, R., Tait, D. S., Brown, V. J., \& Dunnett, S. B. (2013). Lesions of the dorsomedial striatum impair formation of attentional set in rats. Neuropharmacology, 71, 148-153.

Lumme, V., Aalto, S., Ilonen, T., Någren, K., \& Hietala, J. (2007). Dopamine D2/D3 receptor binding in the anterior cingulate cortex and executive functioning. Psychiatry Research: Neuroimaging, 156(1), 69-74.

Malhotra, A. K., Kestler, L. J., Mazzanti, C., Bates, J. A., Goldberg, T., \& Goldman, D. (2002). A functional polymorphism in the COMT gene and performance on a test of prefrontal cognition. American Journal of Psychiatry, 159(4), 652-654. 
Markett, S., Montag, C., Walter, N. T., Plieger, T., \& Reuter, M. (2011). On the molecular genetics of flexibility: The case of task-switching, inhibitory control and genetic variants. Cognitive, Affective, \& Behavioral Neuroscience, 11(4), 644-651. https://doi.org/10.3758/s13415-011-0058-6

Mehta, M. A., Manes, F. F., Magnol, G., Sahakian, B. J., \& Robbins, T. W. (2004). Impaired set-shifting and dissociable effects on tests of spatial working memory following the dopamine d2 receptor antagonist sulpiride in human volunteers. Psychopharmacology, 176, 331-342.

Meiran, N., Diamond, G. M., Toder, D., \& Nemets, B. (2011). Cognitive rigidity in unipolar depression and obsessive compulsive disorder: Examination of task switching, Stroop, working memory updating and post-conflict adaptation. Psychiatry research, 185(1-2), 149-156.

Meyer-Lindenberg, A., Miletich, R. S., Kohn, P. D., Esposito, G., Carson, R. E., Quarantelli, M., Weinberger, D. R., \& Berman, K. F. (2002). Reduced prefrontal activity predicts exaggerated striatal dopaminergic function in schizophrenia. Nature Neuroscience, 5(3), 267271. https://doi.org/10.1038/nn804

Mier, D., Kirsch, P., \& Meyer-Lindenberg, A. (2010). Neural substrates of pleiotropic action of genetic variation in COMT: A meta-analysis. Molecular Psychiatry, 15(9), 918-927. https://doi.org/10.1038/mp.2009.36

Miranda, G. G., Rodrigue, K. M., \& Kennedy, K. M. (2020). Cortical thickness mediates the relationship between DRD2 C957T polymorphism and executive function across the adult lifespan. Brain Structure and Function. https://doi.org/10.1007/s00429-020-02169-5

Morris, L. S., Kundu, P., Dowell, N., Mechelmans, D. J., Favre, P., Irvine, M. A., ... \& Voon, V. (2016). Fronto-striatal organization: defining functional and microstructural substrates of behavioural flexibility. Cortex, 74, 118-133.

Mosiołek, A., Gierus, J., Koweszko, T., \& Szulc, A. (2016). Cognitive impairment in schizophrenia across age groups: a case-control

Niv, Y., Daw, N. D., Joel, D., \& Dayan, P. (2007). Tonic dopamine: opportunity costs and the control of response vigor. Psychopharmacology, 191(3), 507-520.

O’Neill, M., \& Brown, V. J. (2007). The effect of striatal dopamine depletion and the adenosine A2A antagonist KW-6002 on reversal learning in rats. Neurobiology of learning and memory, 88(1), 75-81. 
O’Reilly, R. C. (2013). Individual Differences in Cognitive Flexibility. Biological Psychiatry, 74(2), 78-79. https://doi.org/10.1016/j.biopsych.2013.05.012

Ottaviani, C., Watson, D. R., Meeten, F., Makovac, E., Garfinkel, S. N., \& Critchley, H. D. (2016). Neurobiological substrates of cognitive rigidity and autonomic inflexibility in generalized anxiety disorder. Biological Psychology, 119, 31-41.

Papaleo, F., Burdick, M. C., Callicott, J. H., \& Weinberger, D. R. (2014). Epistatic interaction between COMT and DTNBP1 modulates prefrontal function in mice and in humans. Molecular psychiatry, 19(3), 311-316.

Phillips, P. C. (2008). Epistasis - the essential role of gene interactions in the structure and evolution of genetic systems. Nature Reviews Genetics, 9(11), 855-867.

Poljac, E., Hoofs, V., Princen, M. M., \& Poljac, E. (2017). Understanding behavioural rigidity in autism spectrum conditions: The role of intentional control. Journal of Autism and Developmental Disorders, 47(3), 714-727.

Ragozzino, M. E. (2007). The contribution of the medial prefrontal cortex, orbitofrontal cortex, and dorsomedial striatum to behavioral flexibility. Annals of the New York academy of sciences, 1121(1), 355-375.

Ramakrishnan, S., Robbins, T. W., \& Zmigrod, L. (under review). Cognitive Rigidity, Habitual Tendencies, and Obsessive-Compulsive Symptoms: Individual Differences and Interactions in a Healthy Population.

Raven, J.C. (1938). Raven's progressive matrices. Western Psychological Services.

Ritchie, T., \& Noble, E. P. (2003). Association of Seven Polymorphisms of the D2 Dopamine Receptor Gene with Brain Receptor-Binding Characteristics. Neurochemical Research, 28(1), 73-82. https://doi.org/10.1023/A:1021648128758

Robbins, T. W., \& Arnsten, A. F. T. (2009). The Neuropsychopharmacology of FrontoExecutive Function: Monoaminergic Modulation. Annual Review of Neuroscience, 32(1), 267287. https://doi.org/10.1146/annurev.neuro.051508.135535

Roberts, A. C., Salvia, M. D., Wilkinson, L. S., Collins, P., Muir, J. L., Everitt, B. J., \& Robbins, T. W. (1994). 6-Hydroxydopamine lesions of the prefrontal cortex in monkeys enhance performance on an analog of the Wisconsin Card Sort Test: Possible interactions with 
subcortical dopamine. Journal of Neuroscience, 14(5), 2531-2544. https://doi.org/10.1523/JNEUROSCI.14-05-02531.1994

Rodriguez-Jimenez, R., Hoenicka, J., Jimenez-Arriero, M. A., Ponce, G., Bagney, A., Aragues, M., \& Palomo, T. (2007). Performance in the Wisconsin Card Sorting Test and the C957T Polymorphism of the DRD2 Gene in Healthy Volunteers. Neuropsychobiology; Basel, 54(3), $166-170$.

Roussos, P., Giakoumaki, S. G., \& Bitsios, P. (2009). Tolcapone effects on gating, working memory, and mood interact with the synonymous catechol-O-methyltransferase rs $4818 \mathrm{c} / \mathrm{g}$ polymorphism. Biological psychiatry, 66(11), 997-1004.

Samanez-Larkin, G. R., Buckholtz, J. W., Cowan, R. L., Woodward, N. D., Li, R., Ansari, M. S., Arrington, C. M., Baldwin, R. M., Smith, C. E., Treadway, M. T., Kessler, R. M., \& Zald, D. H. (2013). A Thalamocorticostriatal Dopamine Network for Psychostimulant-Enhanced Human Cognitive Flexibility. Biological Psychiatry, 74(2), 99-105. https://doi.org/10.1016/j.biopsych.2012.10.032

Savitz, J., Solms, M., \& Ramesar, R. (2006). The molecular genetics of cognition: dopamine, COMT and BDNF. Genes, Brain and Behavior, 5(4), 311-328.

Sharpe, M. J., Batchelor, H. M., Mueller, L. E., Chang, C. Y., Maes, E. J., Niv, Y., \& Schoenbaum, G. (2020). Dopamine transients do not act as model-free prediction errors during associative learning. Nature communications, 11(1), 1-10.

Sharpe, M. J., Chang, C. Y., Liu, M. A., Batchelor, H. M., Mueller, L. E., Jones, J. L., ... \& Schoenbaum, G. (2017). Dopamine transients are sufficient and necessary for acquisition of model-based associations. Nature Neuroscience, 20(5), 735-742.

Simpson, E. H., Kellendonk, C., \& Kandel, E. (2010). A possible role for the striatum in the pathogenesis of the cognitive symptoms of schizophrenia. Neuron, 65(5), 585-596.

Soutschek, A., Kozak, R., de Martinis, N., Howe, W., Burke, C. J., Fehr, E., Jetter, A., \& Tobler, P. N. (2020). Activation of D1 receptors affects human reactivity and flexibility to valued cues. Neuropsychopharmacology, 45(5), 780-785. https://doi.org/10.1038/s41386-020$\underline{0617-z}$

Stelzel, C., Basten, U., Montag, C., Reuter, M., \& Fiebach, C. J. (2010). Frontostriatal Involvement in Task Switching Depends on Genetic Differences in D2 Receptor Density. 
Journal of Neuroscience, 30(42), 14205-14212. https://doi.org/10.1523/JNEUROSCI.1062$\underline{10.2010}$

Stelzel, C., Fiebach, C. J., Cools, R., Tafazoli, S., \& D’Esposito, M. (2013). Dissociable frontostriatal effects of dopamine D2 receptor stimulation on cognitive versus motor flexibility. Cortex, 49(10), 2799-2811. https://doi.org/10.1016/j.cortex.2013.04.002

Uddin, L. Q. (2021). Cognitive and behavioural flexibility: neural mechanisms and clinical considerations. Nature Reviews Neuroscience, 1-13.

Ueltzhöffer, K., Armbruster-Genç, D. J., \& Fiebach, C. J. (2015). Stochastic dynamics underlying cognitive stability and flexibility. PLoS Comput Biol, 11(6), e1004331.

Vaghi, M. M., Vértes, P. E., Kitzbichler, M. G., Apergis-Schoute, A. M., van der Flier, F. E., Fineberg, N. A., ... \& Bullmore, E. T. (2017). Specific frontostriatal circuits for impaired cognitive flexibility and goal-directed planning in obsessive-compulsive disorder: evidence from resting-state functional connectivity. Biological psychiatry, 81(8), 708-717.

van Holstein, M., Aarts, E., van der Schaaf, M. E., Geurts, D. E. M., Verkes, R. J., Franke, B., van Schouwenburg, M. R., \& Cools, R. (2011). Human cognitive flexibility depends on dopamine D2 receptor signaling. Psychopharmacology, 218(3), 567-578. https://doi.org/10.1007/s00213-011-2340-2

Volkow, N. D., Gur, R. C., Wang, G. J., Fowler, J. S., Moberg, P. J., Ding, Y. S., ... \& Logan, J. (1998). Association between decline in brain dopamine activity with age and cognitive and motor impairment in healthy individuals. American Journal of psychiatry, 155(3), 344-349.

Wacker, J. (2011). With Great Power Comes Great Responsibility: Meta-Analytic Proof for a $\begin{array}{lllll}\text { Timeless } & \text { Insight. } & \text { Biological } & \text { Psychiatry, }\end{array}$ https://doi.org/10.1016/j.biopsych.2010.08.036

Watanabe, T., Lawson, R. P., Walldén, Y. S., \& Rees, G. (2019). A neuroanatomical substrate linking perceptual stability to cognitive rigidity in autism. Journal of Neuroscience, 39(33), 6540-6554.

Xu, H., Kellendonk, C. B., Simpson, E. H., Keilp, J. G., Bruder, G. E., Polan, H. J., Kandel, E. R., \& Gilliam, T. C. (2007). DRD2 C957T polymorphism interacts with the COMT Val158Met polymorphism in human working memory ability. Schizophrenia Research, 90(1), 104-107. https://doi.org/10.1016/j.schres.2006.10.001 
Yavich, L., Forsberg, M. M., Karayiorgou, M., Gogos, J. A., \& Männistö, P. T. (2007). Sitespecific role of catechol-O-methyltransferase in dopamine overflow within prefrontal cortex and dorsal striatum. Journal of Neuroscience, 27(38), 10196-10209.

Zareyan, S., Zhang, H., Wang, J., Song, W., Hampson, E., Abbott, D., \& Diamond, A. (2021). First Demonstration of Double Dissociation between COMT-Met158 and COMT-Val158 Cognitive Performance When Stressed and When Calmer. Cerebral Cortex, 31(3), 1411-1426. Zhang, S., Zhang, M., \& Zhang, J. (2014). Association of COMT and COMT-DRD2 interaction with creative potential. Frontiers in Human Neuroscience, 8. https://doi.org/10.3389/fnhum.2014.00216

Zmigrod, L. (2020). The role of cognitive rigidity in political ideologies: theory, evidence, and future directions. Current Opinion in Behavioral Sciences, 34, 34-39.

Zmigrod, L., Eisenberg, I. W., Bissett, P. G., Robbins, T. W., \& Poldrack, R. A. (2021). The cognitive and perceptual correlates of ideological attitudes: a data-driven approach. Philosophical Transactions of the Royal Society B, 376(1822), 20200424.

Zmigrod, L., Rentfrow, P. J., \& Robbins, T. W. (2018). Cognitive underpinnings of nationalistic ideology in the context of Brexit. Proceedings of the National Academy of Sciences, 115(19), E4532-E4540.

Zmigrod, L., Rentfrow, P. J., \& Robbins, T. W. (2020). The partisan mind: Is extreme political partisanship related to cognitive inflexibility?. Journal of Experimental Psychology: General, 149(3), 407.

Zmigrod, L., Rentfrow, P. J., Zmigrod, S., \& Robbins, T. W. (2019). Cognitive flexibility and religious disbelief. Psychological research, 83(8), 1749-1759.

Zmigrod, L., Zmigrod, S., Rentfrow, P. J., \& Robbins, T. W. (2019). The psychological roots of intellectual humility: The role of intelligence and cognitive flexibility. Personality and Individual Differences, 141, 200-208. 


\section{Acknowledgements}

We thank NIHR BioResource volunteers for their participation, and gratefully acknowledge NIHR BioResource centres, NHS Trusts and staff for their contribution. We thank the National Institute for Health Research, NHS Blood and Transplant, and Health Data Research UK as part of the Digital Innovation Hub Programme. The views expressed are those of the authors and not necessarily those of the NHS, the NIHR or the Department of Health and Social Care. L.Z. was supported by a Gates Cambridge Scholarship and a Junior Research Fellowship at Churchill College, University of Cambridge for the duration of this research. 


\section{Appendix}

\section{WCST and COMT}

It is also valuable to analyse the data while fractionating the COMT genotype into its three genotype groups (Met/Met, Met/Val, Val/Val). Higher values of the COMT genotype variable thereby reflect a higher number of Val alleles. In the low IQ participants, a regression analysis was conducted predicting WCST accuracy rate from age, gender, and IQ in the first step, and COMT genotype (Met/Met, Met/Val, Val/Val) in the second step. COMT genotype was a significant predictor, indicating that cognitive flexibility decreased with more Val alleles.

Appendix Table A1. Hierarchical regression predicting WCST accuracy rate in the low IQ participants with the three COMT genotype groups.

\section{Regression - Predicting Cognitive Flexibility (Low IQ Sample)}

\begin{tabular}{lllllll}
\hline \multicolumn{2}{l}{ Model } & Unstandardized beta & SE & $\boldsymbol{\beta}$ & $\mathbf{t}$ & $\boldsymbol{p}$ \\
\hline $\mathrm{H}_{0}$ & (Intercept) & 0.649 & 0.038 & & 17.145 & $1.214 \times 10^{51}$ \\
& Age & -0.002 & $4.991 \times 10^{4}$ & -0.172 & -3.896 & $1.120 \times 10^{4}$ \\
& Gender & -0.027 & 0.014 & -0.089 & -2.018 & 0.044 \\
& IQ & 0.030 & 0.006 & 0.236 & 5.411 & $9.971 \times 10^{8}$ \\
$\mathrm{H}_{1}$ & (Intercept) & 0.663 & 0.038 & & 17.332 & $1.748 \times 10^{52}$ \\
& Age & -0.002 & $4.981 \times 10^{4}$ & -0.167 & -3.773 & $1.815 \times 10^{4}$ \\
& Gender & -0.029 & 0.014 & -0.094 & -2.131 & 0.034 \\
IQ & 0.030 & 0.005 & 0.236 & 5.436 & $8.716 \times 10^{8}$ \\
& COMT Genotype (3G) & -0.018 & 0.008 & -0.094 & -2.165 & 0.031 \\
& & & & & \\
& & & df & $\mathbf{R}$ & $\mathbf{R}^{2}$ & $\mathbf{R M S E}$ \\
& $\mathbf{H 1} \mathbf{F}$ & 4,478 & 0.340 & 0.116 & 0.145
\end{tabular}

A hierarchical regression was conducted on the whole participant sample (not fractionating by IQ level), in which age, gender, and IQ (measured by Raven's SPM performance), are included in the first step. The second step in the linear regression includes the COMT genotype split by the three genotype groups (Met/Met, Met/Val, and $\mathrm{Val} / \mathrm{Val}$ ), whereby a higher value indicates 
more Val alleles, as well as the interaction term between IQ and the 3 COMT genotypes. This revealed that when controlling for IQ, the COMT genotype has a significant independent contribution to cognitive flexibility, where more Val alleles are linked to lower accuracy rate on the WCST. In addition, there is a significant interaction between COMT genotype and IQ when predicting cognitive flexibility. This corroborates the main findings demonstrating that IQ moderates the role of COMT in cognitive flexibility.

Appendix Table A2. Hierarchical regression predicting WCST accuracy rate in the whole sample, including an interaction between IQ and the three COMT genotype groups.

Regression - Predicting Cognitive Flexibility (Whole Sample)

\begin{tabular}{|c|c|c|c|c|c|c|}
\hline \multicolumn{2}{|c|}{ Model } & \multirow{2}{*}{$\begin{array}{l}\text { Unstandardized } \\
\text { beta }\end{array}$} & \multirow{2}{*}{$\begin{array}{l}\text { SE } \\
0.021\end{array}$} & \multirow[t]{2}{*}{$\beta$} & \multirow{2}{*}{$\frac{\mathbf{t}}{32.004}$} & \multirow{2}{*}{$\frac{p}{6.674 \times 10^{169}}$} \\
\hline $\mathrm{H}_{0}$ & (Intercept) & & & & & \\
\hline & Age & -0.002 & $2.652 \times 10^{4}$ & -0.184 & -7.256 & $6.587 \times 10^{13}$ \\
\hline & Gender & -0.019 & 0.007 & -0.064 & -2.615 & 0.009 \\
\hline & IQ & 0.025 & 0.002 & 0.333 & 13.308 & $3.982 \times 1038$ \\
\hline \multirow[t]{8}{*}{$\mathrm{H}_{1}$} & (Intercept) & 0.700 & 0.025 & & 28.265 & $3.075 \times 10^{139}$ \\
\hline & Age & -0.002 & $2.648 \times 10^{4}$ & -0.182 & -7.201 & $9.737 \times 10^{13}$ \\
\hline & Gender & -0.019 & 0.007 & -0.064 & -2.593 & 0.010 \\
\hline & IQ & 0.019 & 0.003 & 0.253 & 6.544 & $8.375 \times 10^{11}$ \\
\hline & COMT Genotype (3G) & -0.041 & 0.015 & -0.219 & -2.790 & 0.005 \\
\hline & IQ $*$ COMT Genotype & 0.006 & 0.002 & 0.230 & 2.719 & 0.007 \\
\hline & & $\underline{\mathbf{H}_{1} \mathbf{F}}$ & df & $\mathbf{R}$ & $\mathbf{R}^{2}$ & RMSE \\
\hline & & 63.254 & 5,1390 & 0.431 & 0.185 & 0.134 \\
\hline
\end{tabular}


Appendix Table A3: ANCOVA predicting cognitive flexibility (WCST accuracy) between the three COMT allele groups in the low IQ participants.

\section{COMT (Low IQ)}

\begin{tabular}{llllll}
\hline COMT Genotype & $\mathbf{N}$ & $\mathbf{M}$ & $\mathbf{S E}$ & $\mathbf{9 5 \%}$ CI LB & $\mathbf{9 5 \%}$ CI UB \\
\hline Met/Met & 168 & 0.651 & 0.012 & 0.628 & 0.674 \\
Met/Val & 173 & 0.643 & 0.011 & 0.621 & 0.666 \\
Val/Val & 142 & 0.615 & 0.013 & 0.590 & 0.640 \\
\cline { 2 - 6 } & $\mathbf{S S}$ & $\mathbf{F}$ & $\mathbf{d f}$ & $\boldsymbol{p}$ & $\boldsymbol{\eta}_{\mathbf{p}}^{\mathbf{2}}$ \\
\cline { 2 - 6 } & $\mathbf{0 . 1 0 6}$ & 2.372 & 2,478 & 0.094 & 0.010 \\
\cline { 2 - 6 } Post Hoc Tests & $\mathbf{M}_{\text {diff }}$ & $\mathbf{S E}$ & $\mathbf{t}$ & $\boldsymbol{p}_{\text {tukey }}$ & $\boldsymbol{p}_{\text {bonf }}$ \\
\cline { 2 - 6 } Met/Met vs Met/Val & 0.008 & 0.016 & 0.479 & 0.881 & 1.000 \\
Met/Met vs Val/Val & 0.036 & 0.017 & 2.093 & 0.092 & 0.111 \\
Met/Val vs Val/Val & 0.028 & 0.017 & 1.650 & 0.226 & 0.299
\end{tabular}

$\mathrm{M}=$ Marginal mean, controlling for age and gender. $\mathrm{SE}=$ standard error of mean. $\mathrm{CI}=$ confidence interval. $\mathrm{LB}=$ lower bound. $\mathrm{UB}=$ upper bound. $\mathrm{SS}=$ Type III Sum of Squares for COMT effect on WCST accuracy rate. $\mathrm{M}_{\text {diff }}=$ mean difference. $\mathrm{P}_{\text {tukey }}=$ $\mathrm{p}$-value corrected for multiple comparison with Tukey method. $\mathrm{P}_{\mathrm{bonf}}=\mathrm{p}$-value corrected for multiple comparison with Bonferroni method.

Appendix Table A4: ANCOVA predicting cognitive flexibility (WCST accuracy) between the two homozygote COMT allele groups in the low IQ participants.

COMT (Low IQ)

\begin{tabular}{llllll}
\hline COMT Genotype & $\mathbf{N}$ & $\mathbf{M}$ & $\mathbf{S E}$ & $\mathbf{9 5 \%}$ CI LB & $\mathbf{9 5 \%}$ CI UB \\
\hline Met/Met & 168 & 0.653 & 0.011 & 0.628 & 0.673 \\
Val/Val & 142 & 0.615 & 0.012 & 0.592 & 0.641 \\
\cline { 2 - 6 } & $\mathbf{S S}$ & $\mathbf{F}$ & $\mathbf{d f}$ & $\boldsymbol{p}$ & $\boldsymbol{\eta}_{\mathbf{p}}^{\mathbf{2}}$ \\
\cline { 2 - 6 } & 0.091 & 4.251 & 1,306 & 0.040 & 0.014 \\
Post Hoc Tests & $\mathbf{M}_{\text {diff }}$ & $\mathbf{S E}$ & $\mathbf{t}$ & $\boldsymbol{p}_{\text {tukey }}$ & $\boldsymbol{p}_{\text {bonf }}$ \\
Met/Met vs Val/Val & 0.035 & 0.017 & 2.062 & 0.040 & 0.040
\end{tabular}

$\mathrm{M}=$ Marginal mean, controlling for age and gender. $\mathrm{SE}=$ standard error of mean. $\mathrm{CI}=$ confidence interval. $\mathrm{LB}=$ lower bound. $\mathrm{UB}=$ upper bound. SS=Type III Sum of Squares for COMT effect on WCST accuracy rate. $\mathrm{M}_{\text {diff }}=$ mean difference. $\mathrm{P}_{\text {tukey }}=$ $\mathrm{p}$-value corrected for multiple comparison with Tukey method. $\mathrm{P}_{\mathrm{bonf}}=\mathrm{p}$-value corrected for multiple comparison with Bonferroni method. 
Appendix Table A5: ANCOVA predicting IQ-residualized WCST accuracy rate between the two homozygote COMT allele groups in the low IQ participants.

\section{COMT (Low IQ)}

\begin{tabular}{llllll}
\hline COMT Genotype & $\mathbf{N}$ & $\mathbf{M}$ & $\mathbf{S E}$ & $\mathbf{9 5 \%}$ CI LB & 95\% CI UB \\
\hline Met/Met & 168 & 0.081 & 0.080 & -0.076 & 0.237 \\
Val/Val & 142 & -0.177 & 0.087 & -0.348 & -0.005 \\
\cline { 2 - 6 } & $\mathbf{S S}$ & $\mathbf{F}$ & $\mathbf{d f}$ & $\boldsymbol{p}$ & $\boldsymbol{\eta}_{\mathbf{p}}$ \\
\cline { 2 - 6 } & 5.070 & 4.782 & 1,306 & 0.030 & 0.015 \\
\cline { 2 - 5 } & $\mathbf{M}_{\text {diff }}$ & $\mathbf{S E}$ & $\mathbf{t}$ & $\boldsymbol{p}_{\text {tukey }}$ & $\boldsymbol{p}_{\text {bonf }}$ \\
Met/Met vs Val/Val & 0.258 & 0.118 & 2.187 & 0.030 & 0.030
\end{tabular}

$\mathrm{M}=$ Marginal mean, controlling for age and gender. $\mathrm{SE}=$ standard error of mean. $\mathrm{CI}=$ confidence interval. $\mathrm{LB}=$ lower bound. $\mathrm{UB}=$ upper bound. SS=Type III Sum of Squares for COMT effect on WCST accuracy rate. $\mathrm{M}_{\text {diff }}=$ mean difference. $\mathrm{P}_{\text {tukey }}=$ $\mathrm{p}$-value corrected for multiple comparison with Tukey method. $\mathrm{P}_{\text {bonf }}=\mathrm{p}$-value corrected for multiple comparison with Bonferroni method.

Appendix Table A6: ANCOVA predicting IQ-residualized WCST accuracy rate between the three COMT allele groups in the low IQ participants.

\section{COMT (Low IQ)}

\begin{tabular}{llllll}
\hline COMT Genotype & $\mathbf{N}$ & $\mathbf{M}$ & $\mathbf{S E}$ & $\mathbf{9 5 \%} \mathbf{C I} \mathbf{L B}$ & $\mathbf{9 5 \%} \mathbf{C I}$ UB \\
\hline Met/Met & 168 & 0.083 & 0.081 & -0.076 & -0.076 \\
Met/Val & 173 & 0.029 & 0.080 & -0.127 & -0.127 \\
Val/Val & $\mathbf{1 4 2}$ & -0.182 & 0.088 & -0.355 & -0.355 \\
\cline { 2 - 6 } & $\mathbf{S S}$ & $\mathbf{F}$ & $\mathbf{d f}$ & $\boldsymbol{p}$ & $\boldsymbol{\eta}_{\mathbf{p}}^{\mathbf{2}}$ \\
\cline { 2 - 6 } & $\mathbf{5 . 8 5 2}$ & 2.660 & 2,478 & 0.071 & 0.011 \\
\cline { 2 - 6 } & $\mathbf{M}_{\text {diff }}$ & $\mathbf{S E}$ & $\mathbf{t}$ & $\boldsymbol{p}_{\text {tukey }}$ & $\boldsymbol{p}_{\text {bonf }}$ \\
\cline { 2 - 6 } Met/Met vs Met/Val & 0.053 & 0.114 & 0.470 & 0.885 & 1.000 \\
Met/Met vs Val/Val & 0.264 & 0.120 & 2.205 & 0.071 & 0.084 \\
Met/Val vs Val/Val & 0.211 & 0.119 & 1.773 & 0.180 & 0.231
\end{tabular}

$\mathrm{M}=$ Marginal mean, controlling for age and gender. $\mathrm{SE}=$ standard error of mean. $\mathrm{CI}=$ confidence interval. $\mathrm{LB}=$ lower bound. UB=upper bound. SS=Type III Sum of Squares for COMT effect on IQ-residualized WCST accuracy rate. $\mathrm{M}_{\mathrm{diff}}=$ mean difference. $\mathrm{P}_{\text {tukey }}=\mathrm{p}$-value corrected for multiple comparison with Tukey method. $\mathrm{P}_{\text {bonf }}=\mathrm{p}$-value corrected for multiple comparison with Bonferroni method. 
Appendix Figure A1: IQ-residualized WCST accuracy score by COMT genotype, controlling for age and gender, in low-IQ participants. Error bars indicate standard error of mean.

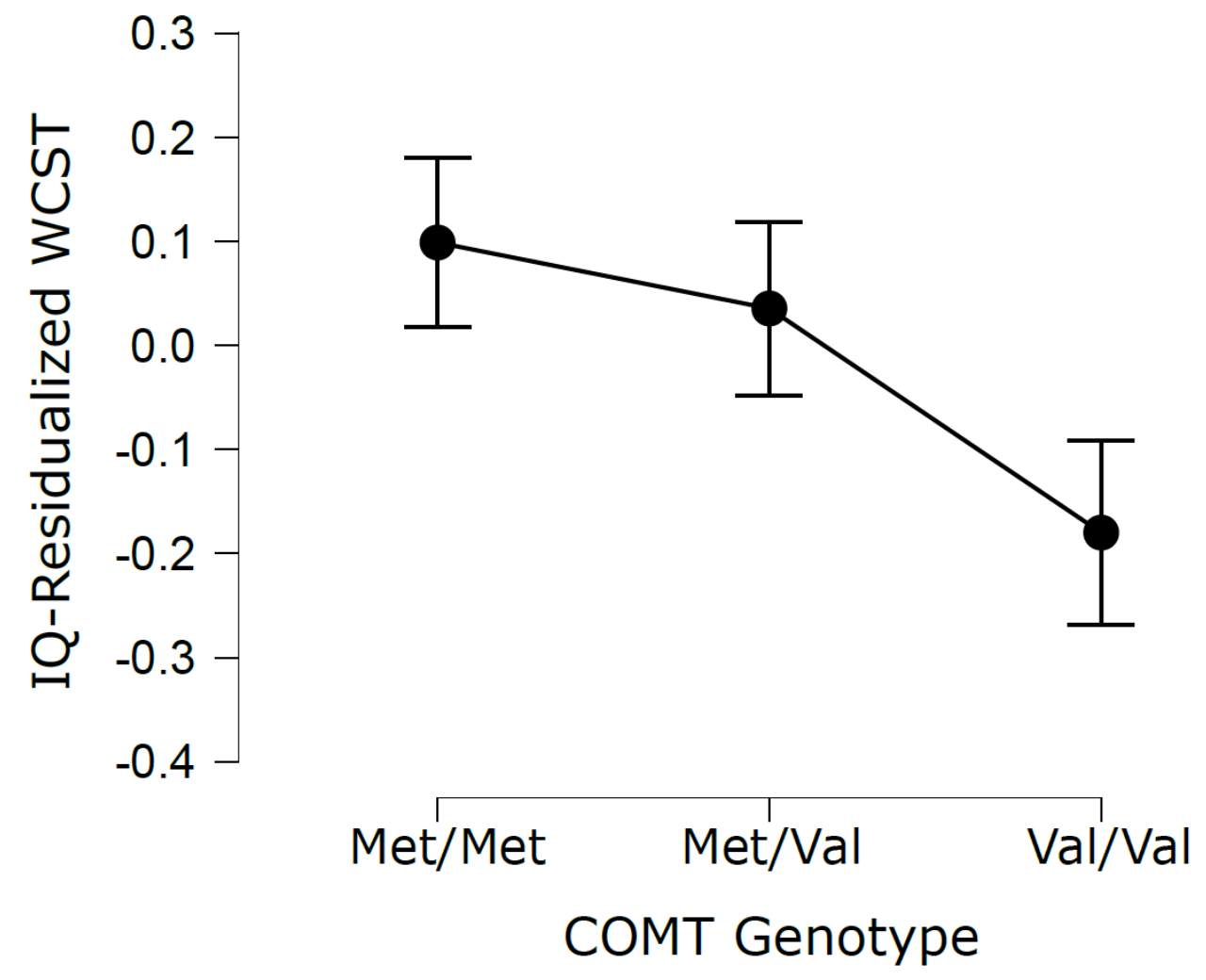

Appendix Table A7. ANCOVA on WCST accuracy rate according to COMT genotype across the whole sample.

\section{COMT (Whole Sample)}

\begin{tabular}{llllll}
\hline COMT Genotype & $\mathbf{N}$ & $\mathbf{M}$ & $\mathbf{S E}$ & $\mathbf{9 5 \%}$ CI LB & 95\% CI UB \\
\hline Met-carriers & 981 & 0.704 & 0.005 & 0.695 & 0.713 \\
Val/Val & 419 & 0.697 & 0.007 & 0.683 & 0.711 \\
\cline { 2 - 6 } & $\mathbf{S S}$ & $\mathbf{F}$ & $\mathbf{d f}$ & $\boldsymbol{p}$ & $\boldsymbol{\eta}_{\mathbf{p}}^{\mathbf{2}}$ \\
\cline { 2 - 6 } & 0.013 & 0.651 & 1,1396 & 0.420 & 0.0005
\end{tabular}

$\mathrm{M}=$ Marginal mean, controlling for age and gender. $\mathrm{SE}=$ standard error of mean. $\mathrm{CI}=$ confidence interval. $\mathrm{LB}=$ lower bound. UB=upper bound. SS=Type III Sum of Squares for COMT effect on WCST accuracy rate. 


\section{WCST and DRD2}

Appendix Table A8: ANCOVA predicting cognitive flexibility (WCST) between the three DRD2 C957T allele groups in the low IQ participants.

DRD2 C957T (Low IQ)

\begin{tabular}{llllll}
\hline DRD2 C957T Genotype & $\mathbf{N}$ & $\mathbf{M}$ & $\mathbf{S E}$ & $\mathbf{9 5 \%}$ CI LB & 95\% CI UB \\
\hline T/T & 131 & 0.662 & 0.013 & 0.636 & 0.687 \\
T/C & 245 & 0.625 & 0.010 & 0.606 & 0.644 \\
C/C & 107 & 0.637 & 0.014 & 0.608 & 0.665 \\
\cline { 2 - 6 } & $\mathbf{S S}$ & $\mathbf{F}$ & $\mathbf{d f}$ & $\boldsymbol{p}$ & $\boldsymbol{\eta}_{\mathbf{p}}^{\mathbf{2}}$ \\
\cline { 2 - 6 } & $\mathbf{0 . 1 1 3}$ & 2.535 & 2,478 & 0.080 & 0.010 \\
Post Hoc Tests & $\mathbf{M}_{\text {diff }}$ & $\mathbf{S E M}$ & $\mathbf{t}$ & $\boldsymbol{p}_{\text {tukey }}$ & $\boldsymbol{p}_{\text {bonf }}$ \\
\cline { 2 - 6 } T/T vs T/C & 0.036 & 0.016 & 2.250 & 0.064 & 0.075 \\
T/T vs C/C & 0.025 & 0.019 & 1.283 & 0.406 & 0.601 \\
T/C vs C/C & -0.011 & 0.017 & -0.659 & 0.788 & 1.000
\end{tabular}

$\mathrm{M}=$ Marginal mean, controlling for age and gender. $\mathrm{SE}=$ standard error of mean. $\mathrm{CI}=$ confidence interval. $\mathrm{LB}=$ lower bound. UB=upper bound. SS=Type III Sum of Squares for DRD2 C957T effect on WCST accuracy rate. $M_{\text {diff }}=$ mean difference. $\mathrm{P}_{\text {tukey }}=\mathrm{p}$-value corrected for multiple comparison with Tukey method. $\mathrm{P}_{\text {bonf }}=\mathrm{p}$-value corrected for multiple comparison with Bonferroni method.

Appendix Table A9. ANCOVA on WCST accuracy rate according to DRD2 C957T genotype across the whole sample.

DRD2 C957T (Whole Sample)

\begin{tabular}{llllll}
\hline DRD2 Genotype & $\mathbf{N}$ & $\mathbf{M}$ & $\mathbf{S E}$ & $\mathbf{9 5 \%}$ CI LB & $\mathbf{9 5 \%}$ CI UB \\
\hline $\mathrm{T} / \mathrm{T}$ & 365 & 0.709 & 0.007 & 0.694 & 0.724 \\
C-carriers & 1035 & 0.699 & 0.004 & 0.690 & 0.708 \\
\cline { 2 - 6 } & $\mathbf{S S}$ & $\mathbf{F}$ & $\mathbf{d f}$ & $\boldsymbol{p}$ & $\boldsymbol{\eta}^{\mathbf{2}} \mathbf{p}$ \\
\cline { 2 - 6 } & 0.026 & 1.261 & 1,1396 & 0.262 & 0.0009
\end{tabular}

$\mathrm{M}=$ Marginal mean, controlling for age and gender. $\mathrm{SE}=$ standard error of mean. $\mathrm{CI}=$ confidence interval. $\mathrm{LB}=$ lower bound. UB=upper bound. SS=Type III Sum of Squares for DRD2 C957T effect on WCST accuracy rate. 


\section{COMT-DRD2 Interactions}

Appendix Table A10. Hierarchical regression and ANCOVA predicting WCST accuracy rate in the whole sample, including an interaction between IQ and the four COMT-DRD2 genotype groups, such that a higher COMT-DRD2 genotype value reflects more COMT Val/Val and DRD2 C-carrier alleles. This corroborates the primary analyses in the whole sample.

Regression - Predicting Cognitive Flexibility (Whole Sample)

\begin{tabular}{llrrrrr}
\hline Model & & $\begin{array}{c}\text { Unstandardized } \\
\text { beta }\end{array}$ & SE & $\boldsymbol{\beta}$ & \multicolumn{1}{c}{ t } & \multicolumn{1}{c}{$\boldsymbol{p}$} \\
\hline $\mathrm{H}_{0} \quad$ (Intercept) & 0.662 & 0.021 & & 32.004 & $6.674 \times 10^{169}$ \\
& Age & -0.002 & $2.652 \times 10^{4}$ & -0.184 & -7.256 & $6.587 \times 10^{13}$ \\
& Gender & -0.019 & 0.007 & -0.064 & -2.615 & 0.009 \\
& IQ & 0.025 & 0.002 & 0.333 & 13.308 & $3.982 \times 10^{38}$ \\
$\mathrm{H}_{1} \quad$ (Intercept) & 0.727 & 0.029 & & 24.730 & $3.364 \times 10^{112}$ \\
& Age & -0.002 & $2.646 \times 10^{4}$ & -0.182 & -7.198 & $9.990 \times 10^{13}$ \\
& Gender & -0.019 & 0.007 & -0.065 & -2.647 & 0.008 \\
& IQ & 0.016 & 0.004 & 0.211 & 4.195 & $2.896 \times 10^{5}$ \\
& COMT-DRD2 Genotypes (4G) & -0.037 & 0.012 & -0.248 & -3.101 & 0.002 \\
& IQ * COMT-DRD2 Genotypes & 0.005 & 0.002 & 0.255 & 2.809 & 0.005
\end{tabular}

\begin{tabular}{rrrrr}
\hline $\mathbf{H}_{\mathbf{1}} \mathbf{F}$ & $\mathbf{d f}$ & $\mathbf{R}$ & $\mathbf{R}^{\mathbf{2}}$ & $\mathbf{R M S E}$ \\
\hline 63.749 & 5,1390 & 0.432 & 0.187 & 0.134
\end{tabular}

ANCOVA - Predicting Cognitive Flexibility (Whole Sample)

\begin{tabular}{lrrrrrr}
\hline \multicolumn{1}{c}{ Cases } & \multicolumn{1}{c}{ SS } & \multicolumn{1}{c}{ df } & Mean Square & \multicolumn{1}{c}{ F } & \multicolumn{1}{c}{$\boldsymbol{p}$} & $\boldsymbol{\eta}^{2}$ \\
\hline Age & 0.926 & 1 & 0.926 & 51.767 & $1.020 \times 10^{12}$ & 0.033 \\
Gender & 0.128 & 1 & 0.128 & 7.171 & 0.007 & 0.005 \\
IQ & 1.948 & 1 & 1.948 & 108.900 & $1.354 \times 10^{24}$ & 0.069 \\
COMT-DRD2 Genotypes (4G) & 0.307 & 3 & 0.102 & 5.727 & $6.802 \times 10^{4}$ & 0.011 \\
IQ * COMT-DRD2 Genotypes & 0.278 & 3 & 0.093 & 5.173 & 0.001 & 0.010 \\
Residuals & 24.799 & 1386 & 0.018 & & & \\
\hline
\end{tabular}

Note. SS=Type III Sum of Squares 
Appendix Table A11: ANCOVA predicting cognitive flexibility (WCST accuracy rate) between A1 carriers and A2/A2 genotypes on the DRD2 ANKK1/Taq1A gene allele groups in the low IQ participants.

DRD2 ANKK1 Taq1A (Low IQ)

\begin{tabular}{llllll}
\hline DRD2 Taq1A Genotype & $\mathbf{N}$ & $\mathbf{M}$ & SE & 95\% CI LB & 95\% CI UB \\
\hline A1-carriers & 252 & 0.639 & 0.009 & 0.620 & 0.658 \\
A2/A2 & 231 & 0.636 & 0.010 & 0.617 & 0.656 \\
\cline { 2 - 6 } & $\mathbf{S S}$ & $\mathbf{F}$ & $\mathbf{d f}$ & $\boldsymbol{p}$ & $\boldsymbol{\eta}_{\mathbf{p}}$ \\
\cline { 2 - 6 } & 0.0007 & 0.035 & 1,479 & 0.582 & 0.00007
\end{tabular}

$\mathrm{M}=$ Marginal mean, controlling for age and gender. $\mathrm{SE}=$ standard error of mean. $\mathrm{CI}=$ confidence interval. $\mathrm{LB}=$ lower bound. $\mathrm{UB}=$ upper bound. SS=Type III Sum of Squares for DRD2 ANKK1/Taq1A effect on WCST accuracy rate.

Appendix Table A12: ANCOVA predicting cognitive flexibility (WCST accuracy rate) between A1 carriers and A2/A2 genotypes on the DRD2 ANKK1/Taq1A gene allele groups across the whole sample.

DRD2 ANKK1 Taq1A (Whole Sample)

\begin{tabular}{llllll}
\hline DRD2 Taq1A Genotype & $\mathbf{N}$ & $\mathbf{M}$ & $\mathbf{S E}$ & $\mathbf{9 5 \%}$ CI LB & 95\% CI UB \\
\hline A1-carriers & 731 & 0.700 & 0.005 & 0.690 & 0.711 \\
A2/A2 & 669 & 0.703 & 0.006 & 0.692 & 0.714 \\
\cline { 2 - 6 } & $\mathbf{S S}$ & $\mathbf{F}$ & $\mathbf{d f}$ & $\boldsymbol{p}$ & $\boldsymbol{\eta}_{\mathbf{p}}$ \\
\cline { 2 - 6 } & 0.003 & 0.150 & 1,1396 & 0.698 & 0.0001
\end{tabular}

$\mathrm{M}=$ Marginal mean, controlling for age and gender. $\mathrm{SE}=$ standard error of mean. $\mathrm{CI}=$ confidence interval. $\mathrm{LB}=$ lower bound $\mathrm{UB}=$ upper bound. SS=Type III Sum of Squares for DRD2 ANKK1/Taq1A effect on WCST accuracy rate.

\section{$\underline{\text { Demographic Characteristics }}$}

Appendix Table A13: Demographic information of the whole sample.

Descriptive Statistics (Whole Sample)

\begin{tabular}{lrrr}
\hline & \multicolumn{1}{c}{ Age } & Gender & Education \\
\hline $\mathrm{N}$ & 1406 & 1426 & 1432 \\
Missing & 28 & 8 & 2 \\
Mean & 54.352 & 0.478 & 3.467 \\
$\mathrm{SD}$ & 14.136 & 0.500 & 1.106 \\
Min & 22.000 & 0.000 & 0.000 \\
Max & 85.000 & 1.000 & 5.000 \\
\hline
\end{tabular}


Frequencies for Ethnicity (Whole Sample)

\begin{tabular}{lrrrr}
\hline \multicolumn{1}{c}{ Ethnicity } & Frequency Percent & $\begin{array}{c}\text { Valid } \\
\text { Percent }\end{array}$ & $\begin{array}{c}\text { Cumulative } \\
\text { Percent }\end{array}$ \\
\hline Asian or Asian British & 18 & 1.255 & 1.258 & 1.258 \\
Black African or Black Caribbean & 15 & 1.046 & 1.048 & 2.306 \\
Hispanic/Latino & 1 & 0.070 & 0.070 & 2.376 \\
Other & 30 & 2.092 & 2.096 & 4.472 \\
White & 1345 & 93.794 & 93.990 & 98.463 \\
White \& Arab & 1 & 0.070 & 0.070 & 98.532 \\
White \& Asian or Asian British & 4 & 0.279 & 0.280 & 98.812 \\
White \& Black African or Black Caribbean & 1 & 0.070 & 0.070 & 98.882 \\
\& Asian or Asian British & 3 & 0.209 & 0.210 & 99.092 \\
White \& Hispanic/Latino & 1 & 0.070 & 0.070 & 99.161 \\
White \& Hispanic/Latino \& Other & 12 & 0.837 & 0.839 & 100.000 \\
White \& Other & 3 & 0.209 & & \\
Missing & 1434 & 100.000 & & \\
Total & & &
\end{tabular}

Appendix Table A14: Demographic information of the whole sample according to COMT genotype.

Descriptive Statistics According to COMT Genotype (Whole Sample)

\begin{tabular}{lrrrrrrrrr}
\hline & \multicolumn{4}{c}{ Age } & \multicolumn{4}{c}{ Gender } & \multicolumn{4}{c}{ Education } \\
& Met/Met & Met/Val & Val/Val & Met/Met & Met/Val & Val/Val & Met/Met & Met/Val Val/Val \\
\hline N & 459 & 527 & 420 & 466 & 532 & 428 & 467 & 537 & 428 \\
Missing & 9 & 10 & 9 & 2 & 5 & 1 & 1 & 0 & 1 \\
Mean & 54.505 & 54.127 & 54.467 & 0.476 & 0.494 & 0.458 & 3.428 & 3.520 & 3.444 \\
SD & 14.289 & 14.263 & 13.833 & 0.500 & 0.500 & 0.499 & 1.116 & 1.069 & 1.141 \\
Min & 23.000 & 22.000 & 24.000 & 0.000 & 0.000 & 0.000 & 0.000 & 0.000 & 0.000 \\
Max & 82.000 & 85.000 & 82.000 & 1.000 & 1.000 & 1.000 & 5.000 & 5.000 & 5.000 \\
\hline
\end{tabular}

Frequencies for Ethnicity According to COMT Genotype (Whole Sample)

\begin{tabular}{llrrr}
\hline \multicolumn{1}{c}{ COMT Ethnicity } & Frequency & Percent & $\begin{array}{c}\text { Valid } \\
\text { Percent }\end{array}$ & $\begin{array}{c}\text { Cumulative } \\
\text { Percent }\end{array}$ \\
\hline Met/Met Asian or Asian British & 2 & 0.427 & 0.428 & 0.428 \\
Black African or Black Caribbean & 5 & 1.068 & 1.071 & 1.499 \\
Hispanic/Latino & 1 & 0.214 & 0.214 & 1.713 \\
Other & 13 & 2.778 & 2.784 & 4.497 \\
White & 440 & 94.017 & 94.218 & 98.715 \\
White \& Asian or Asian British & 2 & 0.427 & 0.428 & 99.143 \\
White \& Hispanic/Latino \& Other & 1 & 0.214 & 0.214 & 99.358 \\
White \& Other & 3 & 0.641 & 0.642 & 100.000 \\
Missing & 1 & 0.214 & & \\
Total & 468 & 100.000 & &
\end{tabular}


Frequencies for Ethnicity According to COMT Genotype (Whole Sample)

\begin{tabular}{|c|c|c|c|c|c|}
\hline COMT & Ethnicity & Frequency & Percent & $\begin{array}{c}\text { Valid } \\
\text { Percent }\end{array}$ & $\begin{array}{l}\text { Cumulative } \\
\text { Percent }\end{array}$ \\
\hline \multirow[t]{11}{*}{ Met/Val } & Asian or Asian British & 9 & 1.676 & 1.676 & 1.676 \\
\hline & Black African or Black Caribbean & 5 & 0.931 & 0.931 & 2.607 \\
\hline & Other & 12 & 2.235 & 2.235 & 4.842 \\
\hline & White & 500 & 93.110 & 93.110 & 97.952 \\
\hline & White \& Arab & 1 & 0.186 & 0.186 & 98.138 \\
\hline & White \& Asian or Asian British & 1 & 0.186 & 0.186 & 98.324 \\
\hline & $\begin{array}{l}\text { White \& Black African or Black } \\
\text { Caribbean \& Asian or Asian British }\end{array}$ & 1 & 0.186 & 0.186 & 98.510 \\
\hline & White \& Hispanic/Latino & 2 & 0.372 & 0.372 & 98.883 \\
\hline & White \& Other & 6 & 1.117 & 1.117 & 100.000 \\
\hline & Missing & 0 & 0.000 & & \\
\hline & Total & 537 & 100.000 & & \\
\hline \multirow[t]{9}{*}{$\mathrm{Val} / \mathrm{Val}$} & Asian or Asian British & 7 & 1.632 & 1.639 & 1.639 \\
\hline & Black African or Black Caribbean & 5 & 1.166 & 1.171 & 2.810 \\
\hline & Other & 5 & 1.166 & 1.171 & 3.981 \\
\hline & White & 405 & 94.406 & 94.848 & 98.829 \\
\hline & White \& Asian or Asian British & 1 & 0.233 & 0.234 & 99.063 \\
\hline & White \& Hispanic/Latino & 1 & 0.233 & 0.234 & 99.297 \\
\hline & White \& Other & 3 & 0.699 & 0.703 & 100.000 \\
\hline & Missing & 2 & 0.466 & & \\
\hline & Total & 429 & 100.000 & & \\
\hline
\end{tabular}

Appendix Table A15: Demographic information of the whole sample according to DRD2 C957T genotype.

Descriptive Statistics According to DRD2 C957T Genotype (Whole Sample)

\begin{tabular}{lrrrrrrrrr}
\hline & \multicolumn{3}{c}{ Age } & \multicolumn{4}{c}{ Gender } & \multicolumn{3}{c}{ Education } \\
& \multicolumn{1}{c}{ TT } & \multicolumn{1}{c}{ TC } & \multicolumn{1}{c}{ CC } & TT & TC & CC & TT & TC & CC \\
\hline N & 366 & 702 & 338 & 372 & 715 & 339 & 374 & 717 & 341 \\
Missing & 8 & 16 & 4 & 2 & 3 & 3 & 0 & 1 & 1 \\
Mean & 54.240 & 54.855 & 53.429 & 0.492 & 0.464 & 0.490 & 3.516 & 3.423 & 3.507 \\
SD & 14.058 & 14.204 & 14.069 & 0.501 & 0.499 & 0.501 & 1.043 & 1.149 & 1.081 \\
Min & 23.000 & 22.000 & 24.000 & 0.000 & 0.000 & 0.000 & 0.000 & 0.000 & 0.000 \\
Max & 82.000 & 85.000 & 80.000 & 1.000 & 1.000 & 1.000 & 5.000 & 5.000 & 5.000 \\
\hline
\end{tabular}




\begin{tabular}{|c|c|c|c|c|c|}
\hline $\begin{array}{l}\text { DRD2 } \\
\text { C957T }\end{array}$ & Ethnicity & Frequency & Percent & $\begin{array}{c}\text { Valid } \\
\text { Percent }\end{array}$ & $\begin{array}{l}\text { Cumulative } \\
\text { Percent }\end{array}$ \\
\hline \multirow[t]{9}{*}{ TT } & Asian or Asian British & 2 & 0.535 & 0.536 & 0.536 \\
\hline & Black African or Black Caribbean & 1 & 0.267 & 0.268 & 0.804 \\
\hline & Hispanic/Latino & 1 & 0.267 & 0.268 & 1.072 \\
\hline & Other & 7 & 1.872 & 1.877 & 2.949 \\
\hline & White & 359 & 95.989 & 96.247 & 99.196 \\
\hline & White \& Hispanic/Latino \& Other & 1 & 0.267 & 0.268 & 99.464 \\
\hline & White \& Other & 2 & 0.535 & 0.536 & 100.000 \\
\hline & Missing & 1 & 0.267 & & \\
\hline & Total & 374 & 100.000 & & \\
\hline \multirow[t]{10}{*}{$\mathrm{TC}$} & Asian or Asian British & 3 & 0.418 & 0.419 & 0.419 \\
\hline & Black African or Black Caribbean & 4 & 0.557 & 0.559 & 0.978 \\
\hline & Other & 15 & 2.089 & 2.095 & 3.073 \\
\hline & White & 681 & 94.847 & 95.112 & 98.184 \\
\hline & White \& Asian or Asian British & 4 & 0.557 & 0.559 & 98.743 \\
\hline & $\begin{array}{l}\text { White \& Black African or Black } \\
\text { Caribbean \& Asian or Asian } \\
\text { British }\end{array}$ & 1 & 0.139 & 0.140 & 98.883 \\
\hline & White \& Hispanic/Latino & 2 & 0.279 & 0.279 & 99.162 \\
\hline & White \& Other & 6 & 0.836 & 0.838 & 100.000 \\
\hline & Missing & 2 & 0.279 & & \\
\hline & Total & 718 & 100.000 & & \\
\hline \multirow[t]{9}{*}{$\mathrm{CC}$} & Asian or Asian British & 13 & 3.801 & 3.801 & 3.801 \\
\hline & Black African or Black Caribbean & 10 & 2.924 & 2.924 & 6.725 \\
\hline & Other & 8 & 2.339 & 2.339 & 9.064 \\
\hline & White & 305 & 89.181 & 89.181 & 98.246 \\
\hline & White \& Arab & 1 & 0.292 & 0.292 & 98.538 \\
\hline & White \& Hispanic/Latino & 1 & 0.292 & 0.292 & 98.830 \\
\hline & White \& Other & 4 & 1.170 & 1.170 & 100.000 \\
\hline & Missing & 0 & 0.000 & & \\
\hline & Total & 342 & 100.000 & & \\
\hline
\end{tabular}


Appendix Table A16: Demographic information of the whole sample according IQ level, determined by Raven's SPM performance.

Descriptive Statistics According to IQ Level

\begin{tabular}{lrrrrrrrrr}
\hline & \multicolumn{3}{c}{ Age } & \multicolumn{3}{c}{ Gender } & \multicolumn{3}{c}{ Education } \\
& Low-IQ & Mid-IQ & Hi-IQ & Low-IQ & Mid-IQ & Hi-IQ & Low-IQ & Mid-IQ & Hi-IQ \\
\hline N & 485 & 257 & 664 & 495 & 264 & 667 & 497 & 265 & 670 \\
Missing & 13 & 8 & 7 & 3 & 1 & 4 & 1 & 0 & 1 \\
Mean & 58.377 & 54.525 & 51.345 & 0.461 & 0.519 & 0.474 & 3.141 & 3.442 & 3.719 \\
SD & 13.524 & 13.281 & 14.174 & 0.499 & 0.501 & 0.500 & 1.240 & 1.114 & 0.919 \\
Min & 24.000 & 23.000 & 22.000 & 0.000 & 0.000 & 0.000 & 0.000 & 0.000 & 0.000 \\
Max & 85.000 & 75.000 & 80.000 & 1.000 & 1.000 & 1.000 & 5.000 & 5.000 & 5.000 \\
\hline
\end{tabular}

